\title{
In vitro formation of Ca-oxalates and the mineral glushinskite by fungal interaction with carbonate substrates and seawater
}

\author{
K. Kolo and Ph. Claeys \\ Vrije Universiteit Brussel, Department of Geology, Pleinlaan 2, 1050 Brussels \\ Received: 21 February 2005 - Published in Biogeosciences Discussions: 15 April 2005 \\ Revised: 19 August 2005 - Accepted: 13 October 2005 - Published: 26 October 2005
}

\begin{abstract}
This study investigates the in vitro formation of Ca-oxalates and glushinskite through fungal interaction with carbonate substrates and seawater as a process of biologically induced metal recycling and neo-mineral formation. The study also emphasizes the role of the substrates as metal donors. In the first experiment, thin sections prepared from dolomitic rock samples of Terwagne Formation (Carboniferous, Viséan, northern France) served as substrates. The thin sections placed in Petri dishes were exposed to fungi grown from naturally existing airborne spores. In the second experiment, fungal growth and mineral formation was monitored using only standard seawater (SSW) as a substrate. Fungal growth media consisted of a high protein/carbohydrates and sugar diet with demineralized water for irrigation. Fungal growth process reached completion under uncontrolled laboratory conditions. The newly formed minerals and textural changes caused by fungal attack on the carbonate substrates were investigated using light and scanning electron microscopy (SEM-EDX), x-ray diffraction (XRD) and Raman spectroscopy. The fungal interaction and attack on the dolomitic and seawater substrates resulted in the formation of Ca-oxalates (weddellite $\mathrm{CaC}_{2} \mathrm{O}_{4} \cdot 2\left(\mathrm{H}_{2} \mathrm{O}\right)$, whewellite $\left(\mathrm{CaC}_{2} \mathrm{O}_{4} \cdot\left(\mathrm{H}_{2} \mathrm{O}\right)\right)$ and glushinskite $\mathrm{MgC}_{2} \mathrm{O}_{4} \cdot 2\left(\mathrm{H}_{2} \mathrm{O}\right)$ associated with the destruction of the original hard substrates and their replacement by the new minerals. Both of $\mathrm{Ca}$ and $\mathrm{Mg}$ were mobilized from the experimental substrates by fungi. This metal mobilization involved a recycling of substrate metals into newly formed minerals. The biochemical and diagenetic results of the interaction strongly marked the attacked substrates with a biological fingerprint. Such fingerprints are biomarkers of primitive life. The formation of glushinskite is of specific importance that is related, besides its importance as a biomineral bearing a recycled $\mathrm{Mg}$, to the possibility of its transformation through diagenetic pathway
\end{abstract}

Correspondence to: K. Kolo

(kakolo@vub.ac.be) into an $\mathrm{Mg}$ carbonate. This work is the first report on the in vitro formation of the mineral glushinskite through fungal interaction with carbonate and seawater substrates. Besides recording the detailed Raman signature of various crystal habits of $\mathrm{Mg}$ - and Ca-oxalates, the Raman spectroscopy proved two new crystal habits for glushinskite. The results of this work document the role of microorganisms as metal recyclers in biomineralization, neo-mineral formation, sediment diagenesis, bioweathering and in the production of mineral and diagenetic biomarkers. They also reveal the capacity of living fungi to interact with liquid substrates and precipitate new minerals.

\section{Introduction}

The formation of Ca-oxalate minerals (weddellite and whewellite) through fungal mediation in various growth environments is well-documented (e.g. Silverman and Munoz, 1970; Arnott, 1982, 1995; Verrecchia et al., 1993; Garieb et al., 1998; Sayer and Gadd, 1997; Gadd, 1999, 2002; Garvie et al., 2000; Verrecchia, 2000; Burford et al., 2002; Gadd et al., 2002; Kolo et al., 2002). This is not the case for glushinskite $\left[\mathrm{MgC}_{2} \mathrm{O}_{4} \cdot 2\left(\mathrm{H}_{2} \mathrm{O}\right)\right]$, where its formation in nature and in vitro (this work) shows that a pre-existing $\mathrm{Mg}$ rich substrate is a prerequisite. Glushinskite, a natural organic magnesium oxalate dihydrate was discovered in 1960 (Wilson et al., 1980). Its natural formation is similar to other organic oxalates (e.g. Ca-oxalates) through fungally mediated mineralization processes (Garvie, 2003). The formation of oxalates contributes to the $\mathrm{Ca}, \mathrm{Mg}$ and $\mathrm{C}$ recycling in nature and to bio-weathering of rock substrates (Ascaso et al., 1998; Arocena et al., 2000; Sterflinger, 2000). Frost et al. (2003) considered the finding of organic oxalates (e.g. weddellite, whewellite, glushinskite) on other planets as a possible evidence of primitive life forms such as lichens and fungi. Microbial mineralization processes (whether bacterial

(C) 2005 Author(s). This work is licensed under a Creative Commons License. 
or fungal) leave mineralogical (metal oxalates) and organic traces on the affected rock surfaces. These traces, when revealed by Raman spectrometry analysis would indicate the existence of a life signature on earth (Howell et al., 2004) or on Mars (Bishop and Murad, 2004; Hochleitner et al., 2004; Howell et al., 2004).

Magnesium can form both simple and complex oxalates (Gadd, 1999). In nature, the formation of glushinskite, as a biomineral, was attributed to the reaction of oxalic acid produced by the fungal mycobiont of the lichen Lecanora atra growing with a Mg-rich substrate of serpentinites (Wilson et al., 1980, 1987). In the case of a rotting saguaro cactus, Garvie (2003) suggested that the reaction between oxalic acid released by fungi and $\mathrm{Mg}$-rich solutions had produced glushinskite. Buildings constructed with $\mathrm{Mg}$-rich limestone or marble could also provide an exposed substrate to fungal interaction and formation of glushinskite under natural conditions. The mineral is also found in human and animal bodies as kidney or urinary tract stones (Diaz-Espineira et al., 1995). Ca-oxalates and glushinskite are considered indicators of biological weathering in $\mathrm{Ca}$ and $\mathrm{Mg}$-rich milieus (Arocena et al., 2003; Wilson et al., 1987).

This experimental study reports on the biomineralization of $\mathrm{Ca}$ and magnesium oxalates produced through free, unselective and un-controlled in vitro fungal growth and interaction with carbonate and seawater substrates that could develop on any suitable surfaces and causes important mineralogical, petrographic alterations of the substrates. Moreover, these alterations could cause permanent damage to works of art. Geologically, fungal interaction will have diagenetic effects on carbonate substrates including mineralogy, petrography and even isotopic signature (Kolo et al., 2004). This is the first report on experimental formation of glushinskite under laboratory conditions simulating natural fungirock substrate environment.

\section{Experimental: materials and methods}

\subsection{Thin sections}

Standard petrographic thin sections $(30 \mu \mathrm{m})$ were prepared from dolomitic rock samples of "Terwagne Formation" (Viséan, Bochaut quarry, in northern France). Detailed petrographic and sedimentological analysis could be found elsewhere (Mamet and Preat, 2005). For two samples, duplicate thin sections were prepared to monitor fungal growth and interaction during the experiment. This made it possible to follow the evolution of the experiment without disturbing the original settings on the other thin sections. The dolomite in the thin sections provided the $\mathrm{Mg}$ and $\mathrm{Ca}$ necessary, either for the reaction with oxalic acid, the main metabolite of fungi or for possible uptake-expulsion by fungi during growth process. The experiment targeted airborne spores naturally inhabiting laboratory and outdoors space especially the saprophytes Mucorales that are commonly referred to as sugar fungi which respond rapidly to and grow rapidly on simple sugars in artificial media besides their ability to break down starch, fats and proteins. These fungi also grow well under a wide $\mathrm{pH}$ range making them tolerant to possible $\mathrm{pH}$ fluctuations during the growth process. The growth media tailored to meet the experiment requirements consisted of ground chips (3-4 mm) of almond seeds as a source of protein and carbohydrates, $10 \%$ sugar solution (dextrose and sucrose) and demineralized water for irrigation. This growth media mixture was found highly efficient for natural, unselective and free fungal growth that produced thick mycelia with high coverage surface area/thin section ratio. Interference with the fungal growth process was minimized to mimic fungal growth under natural outdoor conditions.

Thin sections were placed separately in plastic Petri dishes $(\oslash=90 \mathrm{~mm})$ containing $20 \mathrm{~g}$ of the prescribed natural growth media. The solid chips of growth media surrounded the thin sections but did not touch their surfaces. Ten $\mathrm{mL}$ of sugar solution prepared with demineralized water were carefully added to each Petri dish, taking care not to cover the thin sections surfaces with the solution. Keeping the thin sections surfaces free of growth media and sugar solution was important in monitoring the development of the fungal mass and the extracellular polymeric substance (EPS) layer over the surfaces.

\subsection{Standard seawater (liquid substrate)}

Ten $\mathrm{mL}$ of filtered standard seawater $(3.69 \mathrm{wt} \% \mathrm{Mg}$ and 1.16 wt \% Ca) were added to three Petri dishes containing the same growth media. The standard sea water (SSW) was intended to monitor fungal interaction with liquid substrate and possible recycling of $\mathrm{Ca}$ and $\mathrm{Mg}$ in the biomineralization process. The Petri dishes from both experiments were kept open for $24 \mathrm{~h}$ then were covered and placed in fume hood under continuous air current. Laboratory temperature varied between $23-25^{\circ} \mathrm{C}$. All samples were kept stationary during the course of experiment. No $\mathrm{pH}$ control was carried out. Throughout the experiment, the growing fungi were occasionally spray-irrigated with demineralized water to insure continuous humidity. Specimens of the extracellular polymeric substance (EPS) layer formed on the dolomitic and seawater substrates were continually examined under the optical microscope.

\subsection{Instrumentation}

SEM-EDX: The coating of thin sections, slides of fungal and EPS material, and extracted mineral species was carried out with Carbon Coater EMITECH-Carbon evaporator K450. Acquisition of data concerning biominerals morphology, distribution, chemistry and relationship to fungal mass and EPS layer was carried out using scanning electron microscopy (SEM). The instrument was a JEOL-JSM-6400, working at 
$20 \mathrm{kV}$ and $39 \mathrm{~mm}$ working distance, equipped with energy dispersive system (EDX, Thermo-Noran Pioneer) with a Si$\mathrm{Li}$ detector. The spectra treatment was done using a SUN workstation and the Voyager III software.

Raman spectroscopy: Crystal identification was done by multiple Raman spectroscopy measurements on selected single crystals. The Raman device is a Dilor XY equipped with an Olympus BH2 microscope (50x objective was used simultaneously for illumination and collection) and a liquid nitrogen cooled 1024x256 CCD-3000 detector. The excitation source is a Coherent Innova 70C Argon/Krypton mixed gas laser (excitation at $514.5 \mathrm{~nm}$, laser power at $25 \mathrm{~mW}$ ). Integration time ranged from few to $60 \mathrm{~s}$ per spectral domain. Baseline subtraction and smoothing were performed on the spectra to improve readability. The analyzed crystals are pinpointed by viewing the image of the sample using a TV camera attached to the microscope.

$X$-ray diffraction: A Siemens GADDS-MDS (MicroDiffraction System) was used for the determination of mineral species in mineral clusters within fungal mass, EPS layer, thin section surfaces and extracted crystals.

\section{Results and discussion}

After $48 \mathrm{~h}$, fine whitish and translucent fungal hyphae were observed on the solid growth media in all Petri dishes. Within the fourth day, the fungal hyphae displayed a darker colour and filled the entire space in Petri dishes, Extensive sporulation started within the first week. The growing fungi were identified as Mucor and Rhizopus. Where fungi grew in the Petri dishes, a thick layer ( $\sim 2 \mathrm{~mm}$ thick) consisting of mucilaginous material and hyphal mass, developed beneath the thick mycelium that overlaid both substrate types. Fungi also developed attachment rhizoids on the mineral phase and within the mucilaginous substrate. This mucilaginous material is the extracellular polysaccharide substance (EPS) produced by fungal bioactivity (Jones, 1994; Gadd, 1999; Sterflinger, 2000).

\subsection{Thin section substrates}

The EPS layer ( $\sim 2 \mathrm{~mm}$ thick) came in direct contact with the thin sections surfaces. Microscopic examination carried out every $72 \mathrm{~h}$ on the two thin section duplicates showed progressive fungal attack on the exposed surfaces. Parts of the surfaces displayed evidence of gradual disappearance and disintegration of the original mineral phase conferring a patchy appearance to the exposed surfaces. Newly formed minerals appeared as fine, bright and whitish crystals littering the dolomitic substrates and adhering also to the fungal hyphae that traversed the substrates. Parts of the thin sections that were not covered by fungi or by the EPS layer did not show any signs of attack or new mineral deposition. Under the optical microscope, fresh, untreated specimen from the EPS
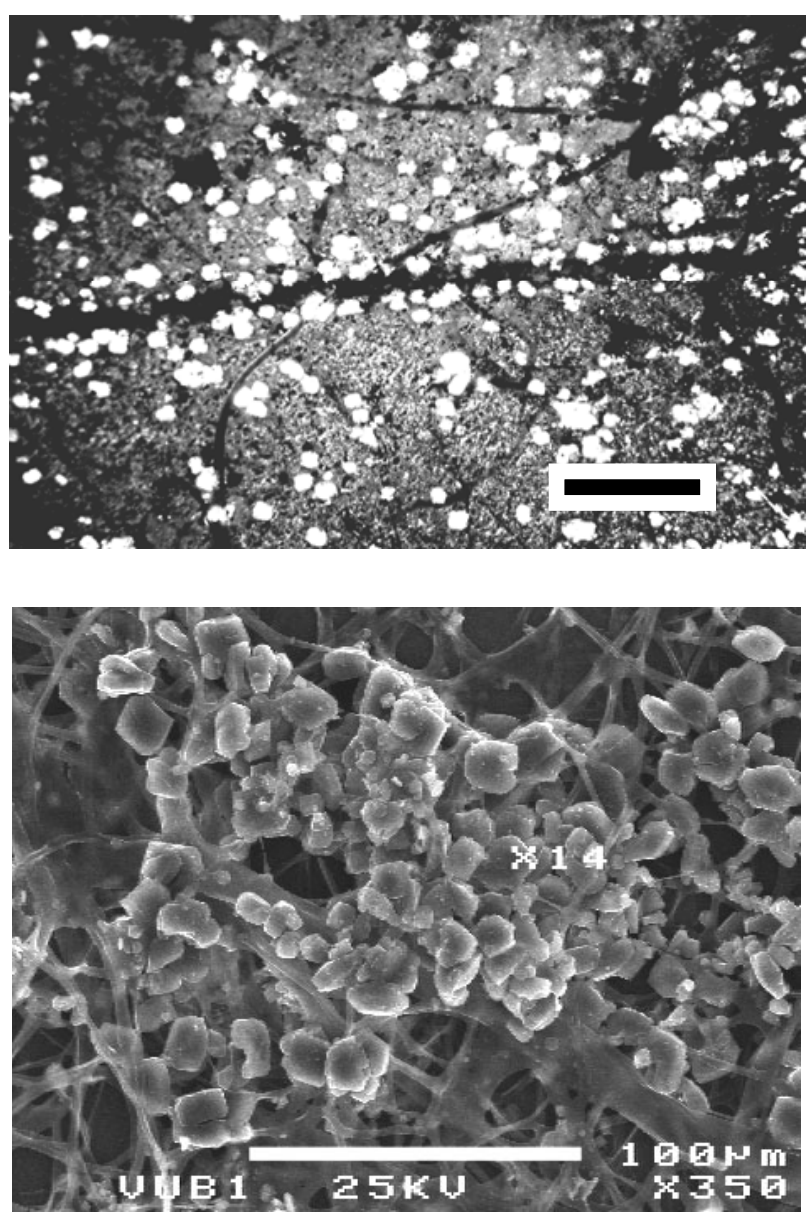

Fig. 1. Clusters of minerals biomineralized by fungal interaction with dolomitic substrate. The minerals (white crystals) are: (a) Attached to fungal hyphae and (b) Embedded in fungal mycelium (black and grey filamentous material). The bead-like ordering of minerals is caused by alignment along hyphal sheaths, revealing a genetic relationship. Optical microscope, XPL. Bar scale $=50 \mu \mathrm{m}$.

layer and mounted on glass slides displayed rich mineral neoformation, crosscut by fungal network (Figs. 1a, b). Total destruction and assimilation of the exposed surfaces of the thin sections was observed by the 15th day of the experiment especially where the fungal-substrate interaction was active. Fresh substrates were formed with new minerals replacing the original dolomite or calcite. At this level of fungal attack, the experiment was considered completed. All thin sections were carefully removed from the Petri dishes, oven dried at $30^{\circ} \mathrm{C}$ for $24 \mathrm{~h}$ and submitted to optical, SEM-EDX XRD and Raman analyses. Fresh and untreated fungal material from the thin section-EPS layer interface was also sampled and mounted on glass slides for similar analysis. The newly formed minerals embedded in fungal mass and EPS layer were extracted by digesting the organic mass in $30 \% \mathrm{H}_{2} \mathrm{O}_{2}$ at $30^{\circ} \mathrm{C}$ for $60 \mathrm{~min}$ in a magnetic stirrer, followed by successive settling, decantation and washings with demineralised water. 
(a)

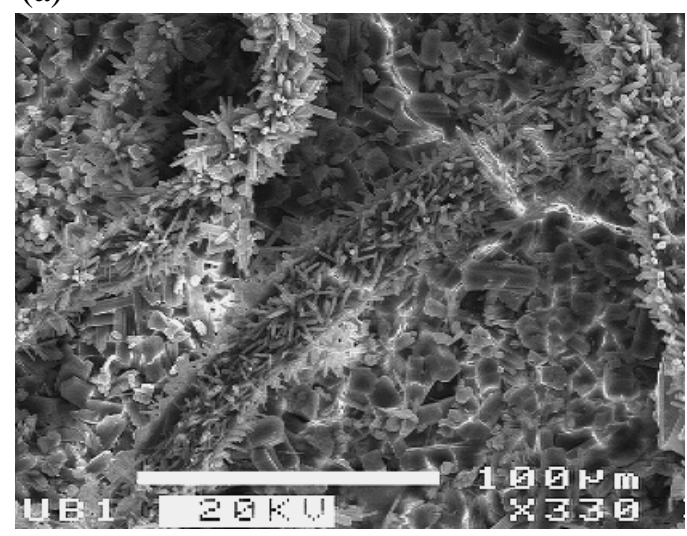

(c)

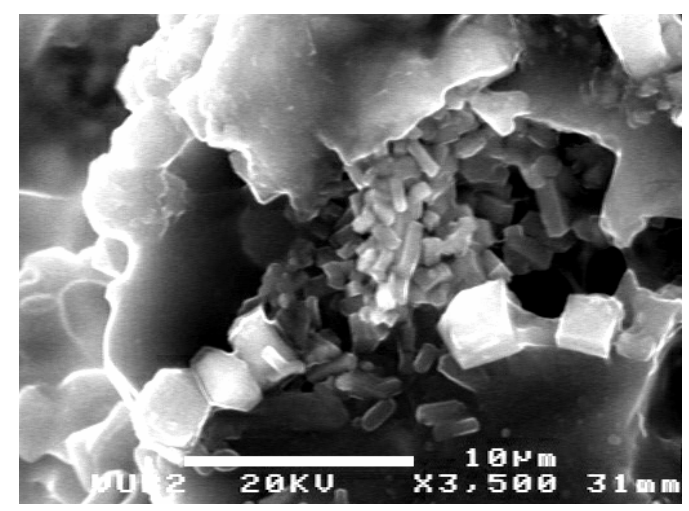

(e)

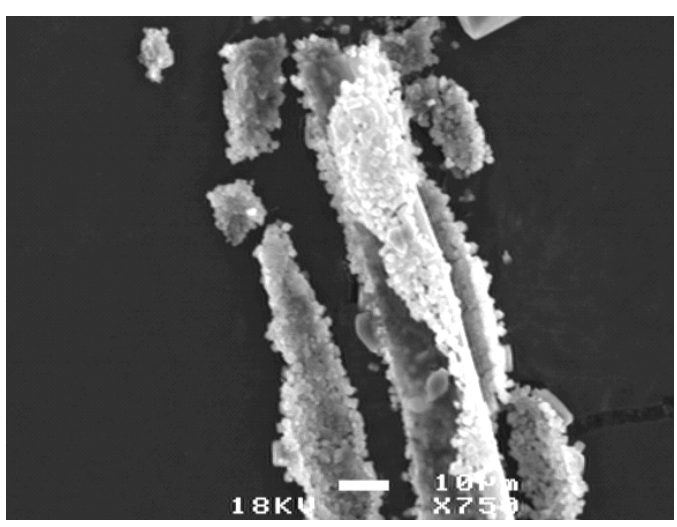

(b)

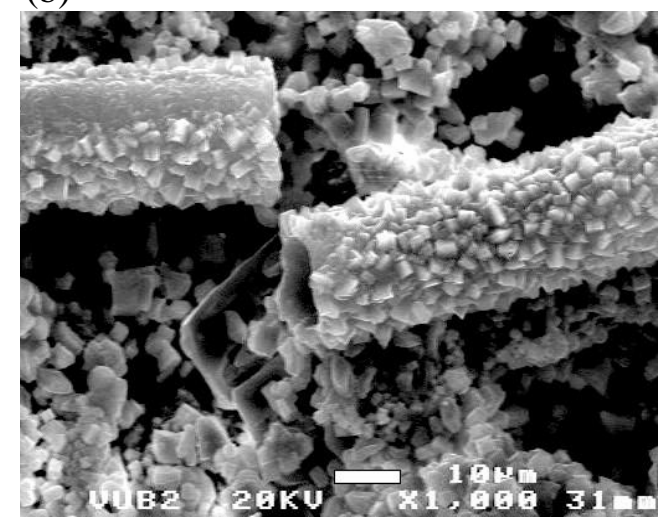

(d)

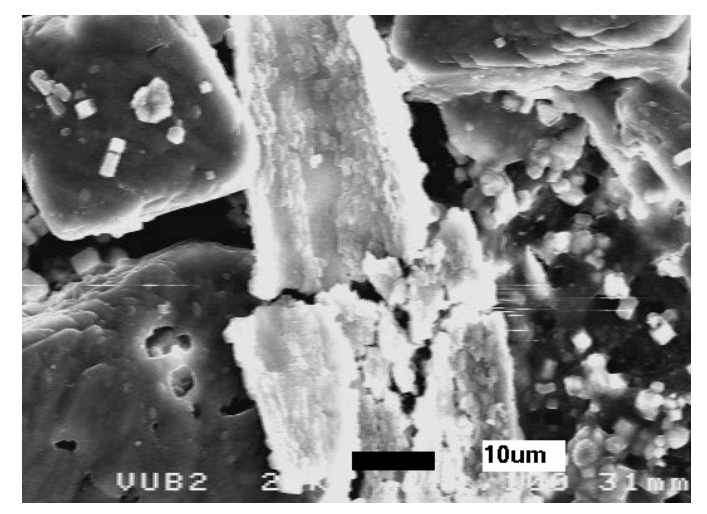

(f)

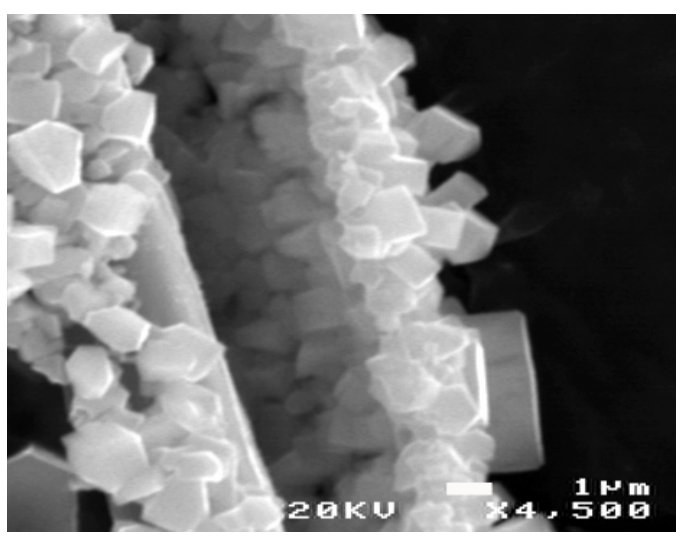

Fig. 2. Scanning electron microscope (SEM) images of dolomitic thin sections attacked by fungi showing forms of mineral neoformations produced by fungal interaction with the dolomitic substrates. (a) Formation of new substrates by replacement or deposition on the original substrate. Dense precipitation of Ca-oxalates forms the new substrate. Heavily biomineralized fungal filaments are also visible. (b) Biomineralization engulfing fungal hyphae. The filaments appear completely encrusted by $\mathrm{Ca}$-oxalates. The background shows a biomineralized new substrate. (c) "Nesting", intra-space filling of a void produced by fungal attack on original matrix grain. The newly produced minerals (prismatic crystals) are "laid" by fungi in the "nest". (d) Hyphal biomineralization. A broken fungal hypha shows Ca-oxalates lining the inner hyphal wall. This suggested an endogenous precipitation of Ca-oxalates. (e) A biomineralized fungal filament extracted from fungal mass. The hypha still preserves its tube shape. The detached fragments show the outer and the inner fungal wall. Both walls are highly mineralized. (f) A detail of (e) showing the Ca-oxalates lining the hyphal wall inside-out. In places, the hyphal wall has been totally replaced by Ca-oxalates. 
(g)

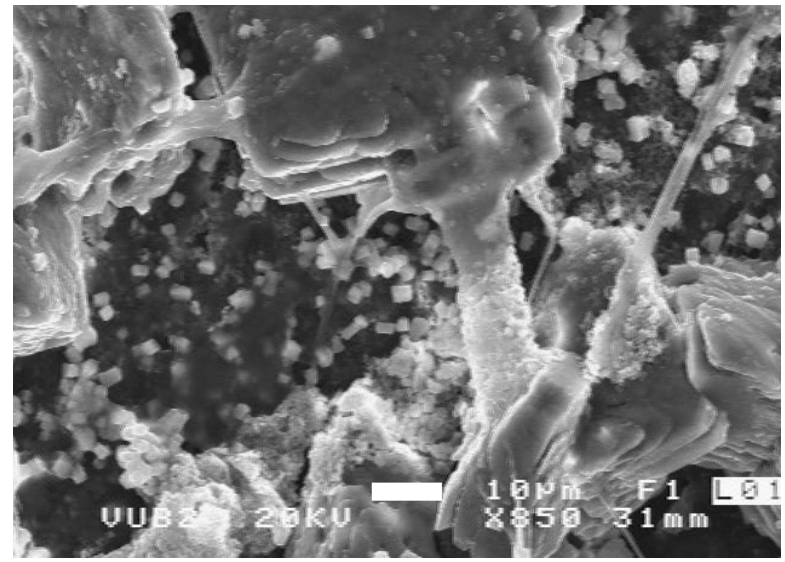

(h)

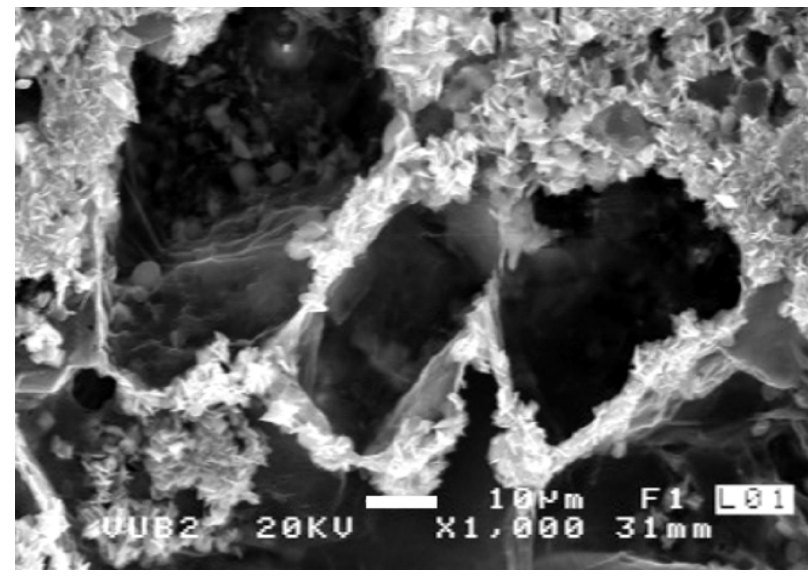

Fig. 2. Continued. (g) Bridging and inter-space filling, fungal biomineralization bridging original attacked dolomite grains. The mineral-bridge is composed of Ca-oxalates. The empty space between the grains is filled with newly produced minerals (Caoxalates). (h) Honey-comb structure formed by preferential deposition of biominerals (Ca-oxalates) on original grain boundaries and void creation by fungal attack and dissolution of those grains. The image also shows the depth of the dissolution. Bar scale: $\mathrm{a}=100 \mu \mathrm{m} ; \mathrm{b}, \mathrm{c}, \mathrm{d}, \mathrm{e}, \mathrm{g}, \mathrm{h}=10 \mu \mathrm{m} ; \mathrm{f}=1 \mu \mathrm{m}$.

The crystals residue was carefully removed from the liquid by suction and mounted on glass slides. The extracted mineral material contained mineral crystals and biomineralized fungal hyphae.

Optical and SEM imagery of attacked thin sections revealed mineral neo-formations that formed definite substrates composed entirely of new minerals. These new substrates covered or replaced the original dolomitic ones. In some areas of the thin sections, the mineralization was intense and the new substrates appeared as densely packed layer of fine-grained crystals 5-20 $\mu \mathrm{m}$ (Fig. 2a). In relation to fungal hyphae, the new minerals appear attached to hy-

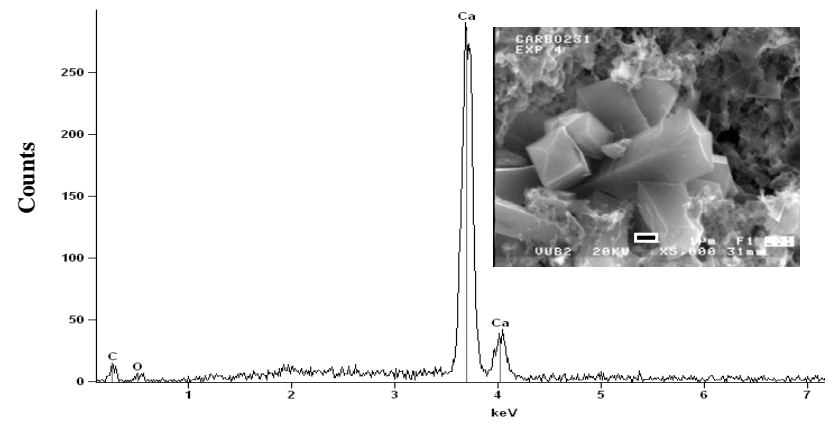

Fig. 3a. Energy dispersive x-ray (EDX) analysis of prismatic and bipyramidal crystals (inserted figure) showing high calcium content with $\mathrm{C}$ and $\mathrm{O}$. These biomineralized crystals making the fine background proved to be composed of Ca-oxalates: weddellite and whewellite.

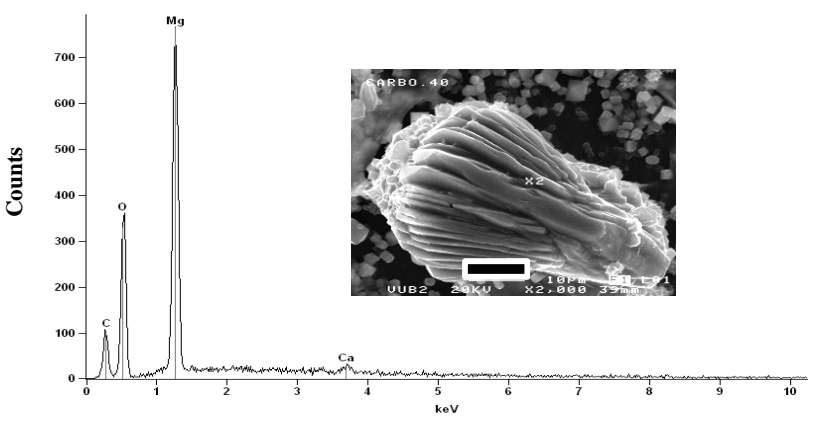

Fig. 3b. Energy dispersive x-ray (EDX) analysis of foliated and spindle shaped crystals (inserted figure) showing high Mg composition. These crystals proved to be the mineral glushinskite.

phae as single, pairs, clusters or beads of crystals external to fungal sheaths. Where mineralization was most active, the newly produced minerals formed an envelope that engulfed the whole fungal sheaths (Figs. 1a, b and 2a, b, d, e, f). Figures $2 \mathrm{e}$ and $\mathrm{f}$ show an interesting intra-hyphal wall mineralization where newly formed minerals formed an inner lining that extends externally through the wall. Through dissolution, fungi created voids between and within the grains of the carbonate substrates, which were subsequently filled by mineral neo-formations (Fig. 2c). Mineral neo-formations also precipitated at the rim of the grains, as fringing and bridging crystals (Figs. $2 \mathrm{~g}$, h). EDX analysis of the new minerals deposited on thin sections or attached to the fungal material revealed two different chemical compositions with distinct crystal habits.

The EDX spectrum of the first group represented by prismatic and bipyramidal crystal habits showed a $\mathrm{Ca}, \mathrm{C}$, and $\mathrm{O}$ (Fig. 3a) composition. Bipyramidal crystals formed the bulk of the newly precipitated crystals on the thin section surfaces. The second group with lamellar spindle shapes that appeared under optical microscope as striations produced a composition of $\mathrm{Mg}, \mathrm{C}$, and $\mathrm{O}$ peaks (Fig. 3b). The lamellas appear 


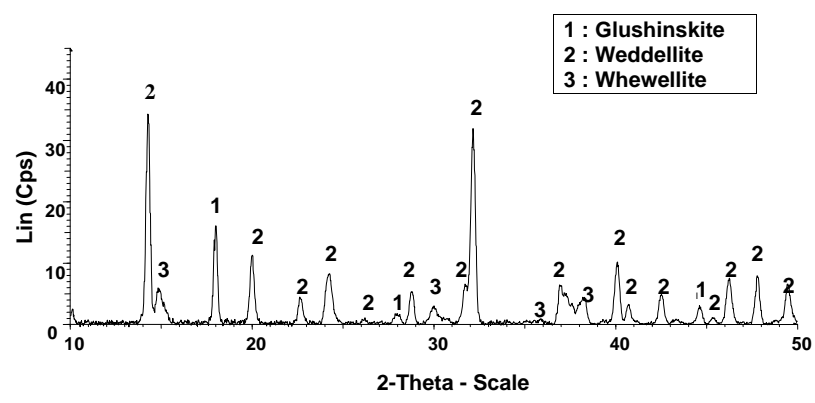

Fig. 4. XRD analysis of mineral neoformations. The identified minerals are Ca-oxalates: weddellite and whewellite as the main phase. Glushinskite appears in the background.

to be originating from a central longitudinal axis. XRD analysis confirmed the Ca-oxalates (weddellite and whewellite) identity of the first group of minerals. The second group was identified as glushinskite (Fig. 4).

Glushinskite crystals like the Ca-oxalates also showed strong association with fungal hyphae. While the $\mathrm{Ca}$ oxalates formed ordered and packed encrustation enveloping fungal hyphae (Fig. 2a, b and 2e, f); glushinskite adhered to hyphae as single large crystals (Figs. 5a, b). This association reveals a genetic relationship with fungal hyphae for both mineral groups.

The Raman spectra (Fig. 6) of a selected single large crystal gave intense band at $1474 \mathrm{~cm}^{-1}$ and low band at $1417 \mathrm{~cm}^{-1}$ corresponding to the symmetric $\mathrm{C}=\mathrm{O}$ stretching vibration, which is cation-mineral dependant (Frost et al., 2003). A low band corresponding to anti-symmetric stretching region appears at $1629 \mathrm{~cm}^{-1}$ and a high band in the $v$ (C-C) stretching region at $913 \mathrm{~cm}^{-1}$. A low band is observed in the C-C-O bending region at $502 \mathrm{~cm}^{-1}$. The 193 , $225,234 \mathrm{~cm}^{-1}$ triplet appear in the low wavenumber region. These bands correspond to OMO ring bending mode. In the hydroxyl-stretching region, a low broad band appears at 3462 $\mathrm{cm}^{-1}$. These values are in good agreement with the published Raman data for calcium oxalate di-hydrate (Frost et al, 2003a). Whewellite (Ca-oxalate monohydrate) was not identified.

The Raman analysis of the large, foliated, spindle shaped and $\mathrm{Mg}$-bearing crystals produced a different signature (Fig. 7). In the symmetric $\mathrm{C}=\mathrm{O}$ stretching region appears an intense band at $1470 \mathrm{~cm}^{-1}$ that is associated with a shoulder band at $1445 \mathrm{~cm}^{-1}$. Other bands appear at 3369, 1720, 1638, $920,584,528,272,232$ and $124 \mathrm{~cm}^{-1}$. These bands are in good agreement with published data (Frost et al., 2003a, b, $2004 \mathrm{a}, \mathrm{b}$ ) and are assigned here to the magnesium oxalate mineral glushinskite. All other measurements on similar crystals produced relatively high intensities with good resolution in the low and high wavenumber regions.

A peculiar spectrum was obtained from a prismatic crystal attached to fungal hyphae. The spectrum (Fig. 8) gave
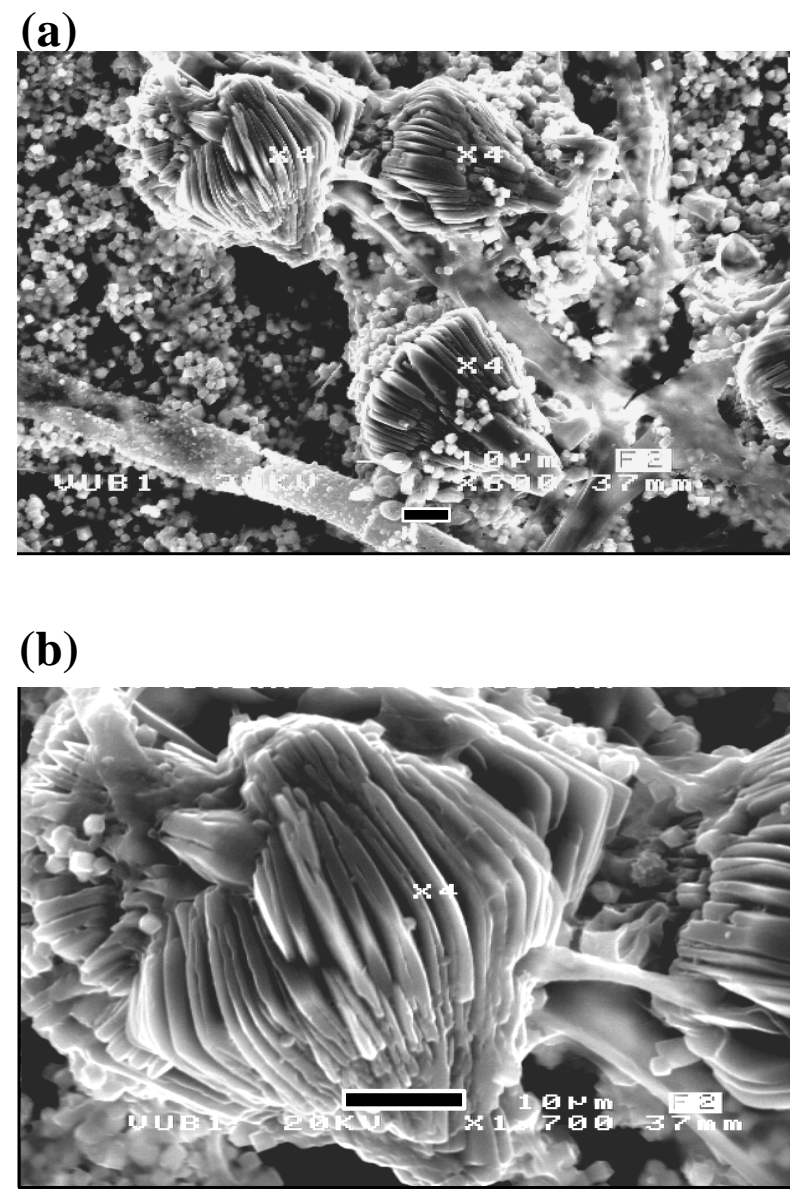

(c)

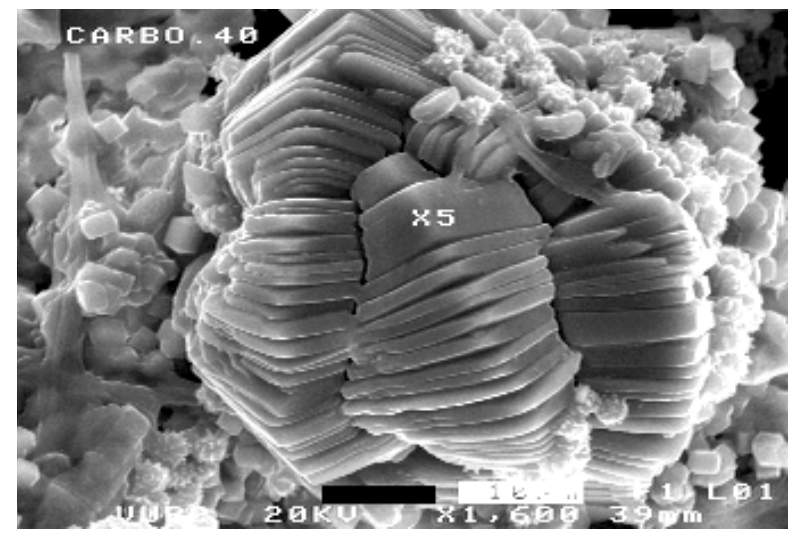

Fig. 5. The peculiar forms of glushinskite crystals revealing the lamellar and foliated spindle habits. (a) Glushinskite crystals adhering to hyphae as single large $(40 \mu \mathrm{m})$ crystals; in the background the much finer Ca-oxalates are visible. (b) and (c) Multiple growths of glushinskite crystals $(40-60 \mu \mathrm{m})$ in twinning formations showing the same lamellar habits. This association reveals a genetic relationship with fungal hyphae. 


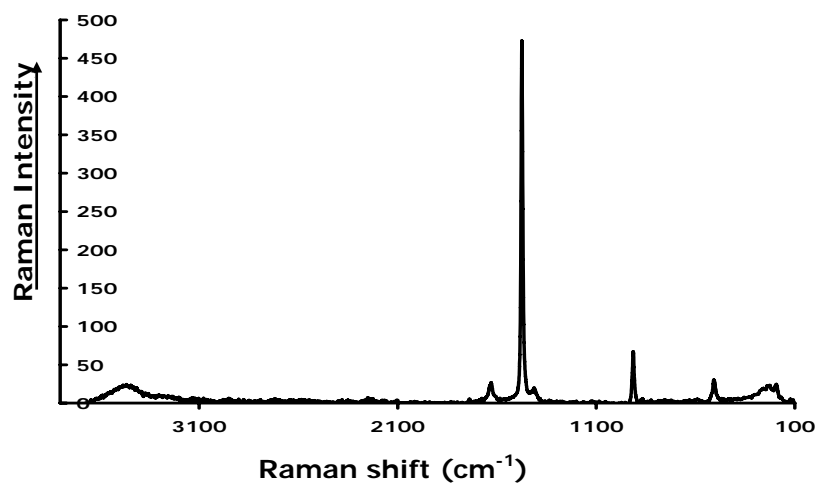

Fig. 6. Raman spectrum of prismatic bipyramidal crystals extracted from fungal mass attacking dolomitic substrate in vitro. The spectrum obtained from single crystal analysis was cross-checked by repeated measurements on several other crystals. The spectrum is typical for weddellite.

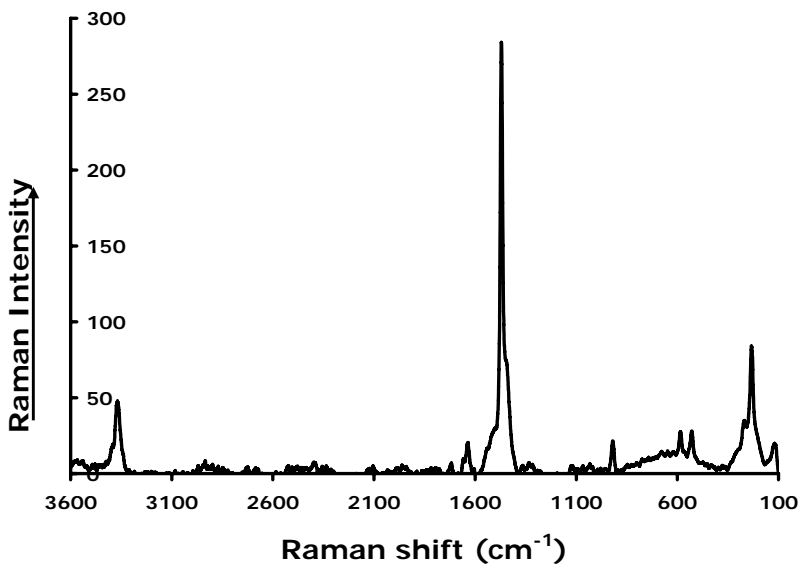

Fig. 7. Raman spectrum of lamellar and spindle shaped crystals extracted from fungal mass attacking dolomitic substrate in vitro. Raman analysis identified these crystals (after EDX assertion of their high $\mathrm{Mg}$ content) as the Mg-oxalate glushinskite. The crystals produced typical glushinskite spectrum.

intense band at $1051 \mathrm{~cm}^{-1}$ that could be assigned to carbonate bonded to a metal with water coordinated to it. The bands 749,714 and $528 \mathrm{~cm}^{-1}$ are associated with this carbonate. The spectrum does not agree with dolomite or calcite. The other bands (low intensity bands) at high and low wavenumbers reveal a signature of both calcium and magnesium oxalates (weddellite and glushinskite) existing in low concentrations in the same crystal.

\subsection{Seawater substrate}

The fungal interaction with the standard seawater substrate produced $7.6 \mathrm{mg}$ of biominerals after extraction from the organic mass (fungal and EPS layer). This quantity is quite large. It reveals considerable biomineralization in only 15

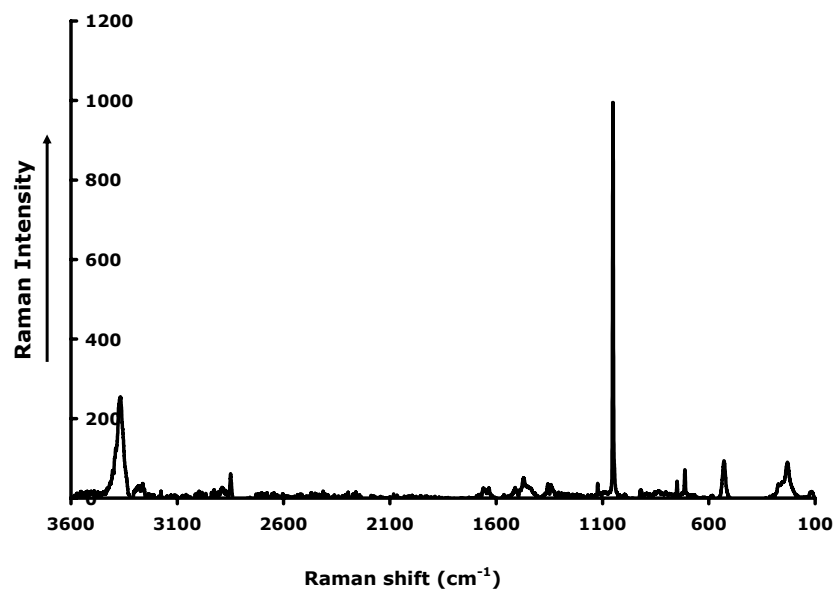

Fig. 8. Raman spectrum of a crystal with mixed signatures of an unidentified carbonate mineral and weddellite. The XRD analyses of the newly formed biominerals did not produce any of the usual carbonate signatures (dolomite or calcite).

days. At the same time, it is a clear manifestation of the role of fungi in modifying the substrate system by addition and subtraction of minerals

Under optical and SEM microscopy, the specimens showed rich biomineral content forming encrustations, clusters or beads on fungal hyphae traversing the EPS layer (Figs. 9a, b, c). The lower parts of the hyphae embedded in the EPS layer were specifically highly biomineralized. The hyphal parts outside EPS layer did not produce biominerals encrustations, clusters or free crystals. This implies a genetic relationship combining the EPS layer and fungal hyphae in the biomineralization process. Biomineral crystals attached to fungal hyphae were mainly tetragonal bipyramidal and tetragonal prismatic-bipyramidal with well-developed $\{101\}$ and $\{100\}$ crystal faces. These forms are normally attributed to Ca-oxalates (Arnott, 1995; Verrecchia 2000; Préat et al., 2003). The same morphologies occurred as free crystals in the fungal mass within the EPS layer (Figs. 9a, b).

Some of the Ca-oxalates crystals revealed a unique and interesting crystal habit (Figs. 9d-e). The new crystal habit shows a prism $(20-25 \mu \mathrm{m})$ with two prismatic-pyramidal endings forming a "Greek Pillar". Some of these "Greek Pillar" crystals formed clusters that radiate from a central point (Fig. 9e) Sceptre crystal habits are known for amethyst. But those have only single end crystal re-growth. The new biomineralized ca-oxalates appear to show a two-end regrowth.

The EDX analysis of the hyphal and EPS crystals revealed a composition of calcium and magnesium respectively. The magnesium bearing crystals represent more than $90 \%$ of the extracted crystals. Ca-bearing crystals formed the rest of the extract. The Ca crystals occurred mainly as encrustations on the hyphal sheath. XRD analysis of organic mass and extract revealed two mineral groups: Ca-oxalates (weddellite and 

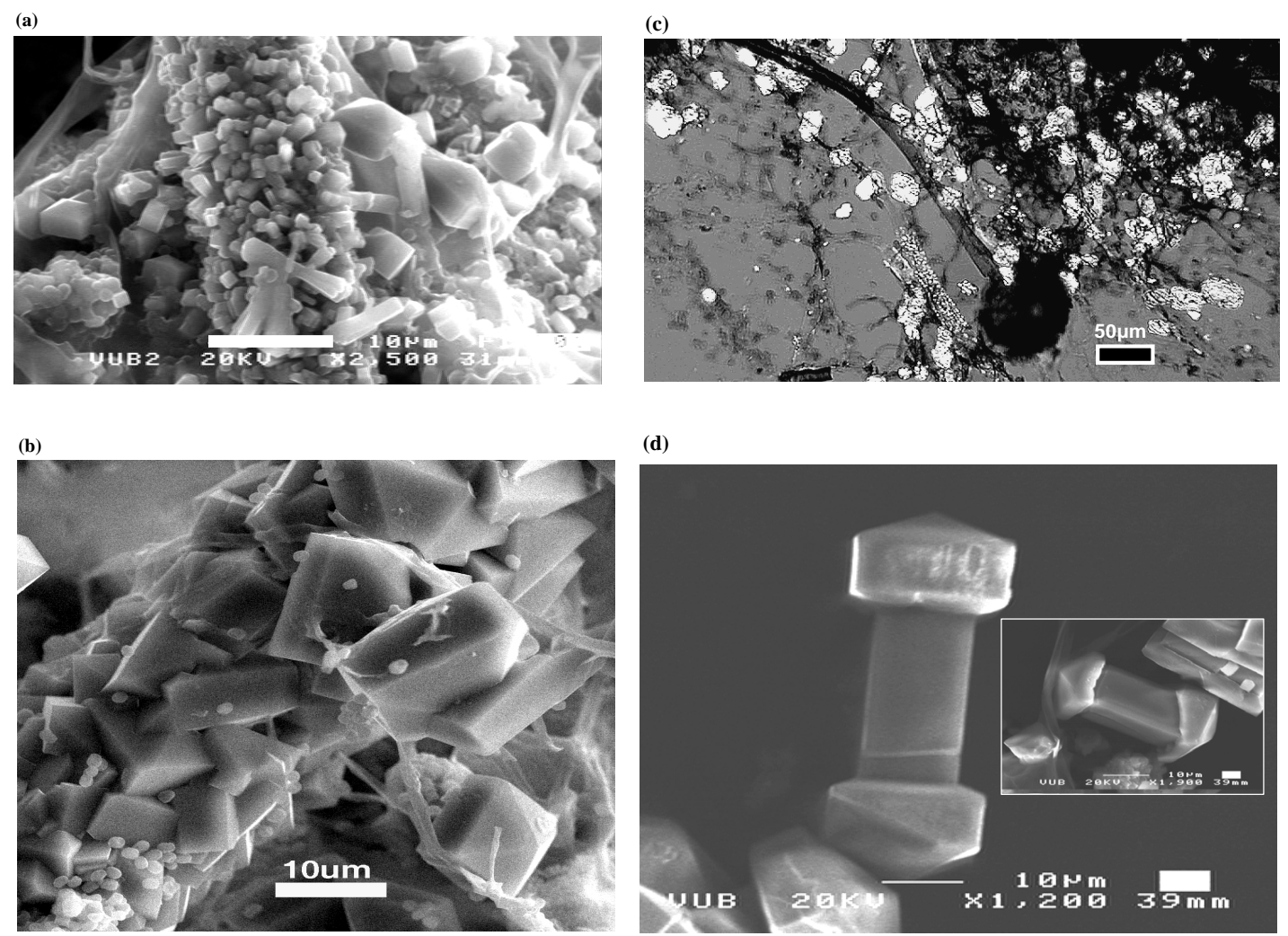

(d)

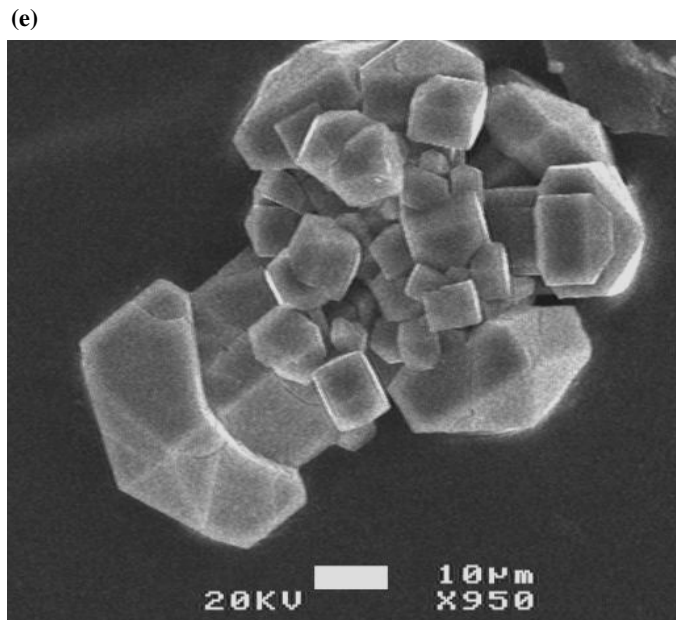

Fig. 9. (a) SEM image showing fungal specimen with rich biomineral contents forming highly ordered and packed crystal encrustations on fungal hyphae. The crystals forms are mainly tetragonal prismatic and bipyramidal typical of weddellite. The background also shows numerous free isolated weddellite crystals. These latter forms are exogenously formed. (b) Same as above but with excellently developed tetragonal prismatic bipyramidal crystal forms of weddellite, some showing penetration twinning. Free crystals embedded in fungal mass but not forming part of crystal encrustations are also visible. (c) A typical experimental fungal mass showing the high content of biominerals forming clusters or beads of crystals (bright spots) either attached to fungal hyphae or filling the space within the fungal mass. Optical microscope. XPL. (d) New crystal habit of Ca-oxalates (weddellite) showing a "Greek Pillar" shape. The prism in the middle is topped by two tetragonal pyramidal forms, entirely different from the "Sceptre" habits known for quartz. The inserted image shows the prism "plugged" into the two pyramidal endings. (Material extracted from fungal mass). (e) Cluster of "Greek Pillar" Ca-oxalates crystals radiating from a central point. One of them is showing twinning. (Material extracted from fungal mass). In (a), (b) and (c), the lower parts of the hyphae embedded in the EPS layer were highly biomineralized. The hyphal parts outside EPS layer did not produce biomineral encrustations, clusters or free crystals. 
whewellite) and glushinskite (Fig. 10). Glushinskite formed the dominant mineral phase in the XRD spectra.

Free crystals extracted from the EPS layer show platy habits (Figs. 11a, b) and coffin shaped habits that are either distorted pyramidal or typical monoclinic $2 / \mathrm{m}$ symmetry forms (Figs. 11c, d). The distorted pyramidal crystals bear transversal lines resembling striations. These lines indicate crystal growth. The platy (pinacoidal) and coffin shaped crystals (Figs. 11a, d) are new crystal habits for glushinskite forming in fungal culture.

Prismatic-bipyramidal crystals produced a Raman spectrum of weddellite. Whewellite was not clearly identified in the analysis, probably due to its very low level of concentration. The spectrum (Fig. 12) shows complexity especially at low and high bands. Intense bands are observed at $1631,1474,913,600,506,148$ and $121 \mathrm{~cm}^{-1}$, broad band at $250 \mathrm{~cm}^{-1}$ and weak band at $198 \mathrm{~cm}^{-1}$. The major intense band at $1474 \mathrm{~cm}^{-1}$ is assigned to the $\mathrm{C}=\mathrm{O}$ symmetric stretching mode. The observation of a single band at $1474 \mathrm{~cm}^{-1}$ indicates the equivalence of $\mathrm{C}=\mathrm{O}$ stretching vibrations and a centrosymmetric structure. The band is attributed to weddellite. The intense band at $1631 \mathrm{~cm}^{-1}$ appears in antisymmetric stretching region. This band is Raman forbidden. The band is observed probably because the structure is a distorted square antiprism (Frost and Weier, 2003a, b). This band is also attributed to weddellite. A single intense band is observed at $913 \mathrm{~cm}^{-1}$ and is attributed to the C-C stretching vibration in weddellite. The Raman spectrum of the low wavenumber region of the mineral shows three Raman bands in the 400$600 \mathrm{~cm}^{-1}$ region. The doublet bands at 600 and $598 \mathrm{~cm}^{-1}$ and the intense band at $506 \mathrm{~cm}^{-1}$ have been assigned to the bending mode of C-C-O and the M-O ring and $\mathrm{M}-\mathrm{O}$ stretching modes. The broad band centred at $250 \mathrm{~cm}^{-1}$ and the band observed at $198 \mathrm{~cm}^{-1}$ is attributed to the $\mathrm{Ca}-\mathrm{O}$ bending and stretching modes. The position of these bands is in good agreement with previous data on weddellite (Frost et al., 2003a). The bands 148 and $121 \mathrm{~cm}^{-1}$ are new bands that have not been reported in previous studies on Ca-oxalates (Frost et al., 2003a, b, 2004a). Only the tetragonal prismatic bipyramidal crystals of weddellite produced these bands. Tetragonal bipyramidal crystals of the same mineral did not yield these very low wavenumber bands. This suggests a structural control at molecular level related to crystal habit since the measurements were done on the $\{100\}$ plane of the prismatic bipyramidal crystals and on $\{101\}$ plane for the bipyramidal crystals. The hydroxyl-stretching region is also complex. This region shows two broad bands centered at 3483 and $3281 \mathrm{~cm}^{-1}$. The first band agrees well with published data on whewellite. The second band is reported here for the first time. The low intensity band at $3072 \mathrm{~cm}^{-1}$ is attributed to weddellite and the $2935 \mathrm{~cm}^{-1}$ could be assigned to organic impurities. The hydroxyl-stretching region is showing a partially dehydrated weddellite that also bears a whewellite signature.

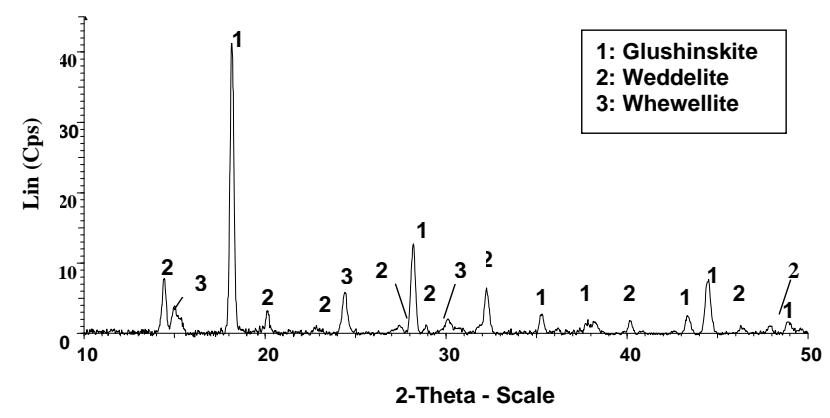

Fig. 10. XRD analysis of fungal mass and extracted biominerals showing two groups: Ca-oxalates (weddellite and whewellite) and Mg-oxalate (glushinskite) produced through fungal interaction with standard sea water substrate. Glushinskite formed the major mineral phase in the XRD spectra as well as in the extract.

Extracted crystals representing coffin shaped (distorted pyramidal and prismatic) and platy crystals were selected for Raman analysis. The EDX analysis of all these crystal types indicated a $\mathrm{Mg}$ peak only. The three crystal forms, although indicating glushinskite, gave slightly different $\mathrm{Ra}-$ man spectra (Figs. 13, 14 and 15). The distorted pyramidal crystals produced intense bands at $3363,1470,586,532$ and $231 \mathrm{~cm}^{-1}$ and low intensity bands at 1643,1659 and 914 and $271 \mathrm{~cm}^{-1}$. The prismatic crystals show intense bands at $3368,1470,920,585,529,230,153$, and $117 \mathrm{~cm}^{-1}$ and moderate bands at 3292, 2902, 1643, 1329 and $274 \mathrm{~cm}^{-1}$. The platy crystals produced a simpler Raman spectrum with major intense bands observed at 3377 and $229 \mathrm{~cm}^{-1}$ and low intensity bands at 1470,914 and $529 \mathrm{~cm}^{-1}$. All three spectra are in agreement with the previous Raman signature of glushinskite obtained on the spindle crystals. Only the prismatic crystals show low wavenumbers at 152 and $117 \mathrm{~cm}^{-1}$. The distorted bipyramidal crystal forms of glushinskite have been previously reported (Wilson et al., 1987). The prismatic coffin shaped and platy morphologies are reported here for the first time.

\subsection{Ca- and Mg-oxalates formation}

All fungal taxa precipitate calcium oxalate on fungal mycelia (Urbanus et al., 1978). This process is considered as detoxification of excess calcium in the fungal growth environment. Fungi and the carbon source they use determine the growth and form of calcium oxalates crystals precipitated on fungal hyphae (Whitney and Arnott, 1988). Oxalic acid, the principal fungal metabolite reacts with the available $\mathrm{Ca}^{2+}$ in the growth environment to precipitate $\mathrm{Ca}$-oxalates:

$\mathrm{C}_{2} \mathrm{O}_{4}^{2-}+\mathrm{Ca}^{2+} \rightarrow \mathrm{CaC}_{2} \mathrm{O}_{4}$

The formation of calcium oxalate monohydrate $\left[\mathrm{CaC}_{2} \mathrm{O}_{4} \cdot \mathrm{H}_{2} \mathrm{O}\right.$ : whewellite] and calcium oxalate dihydrate $\left[\mathrm{CaC}_{2} \mathrm{O}_{4} \cdot 2 \mathrm{H}_{2} \mathrm{O}\right.$ : weddellite] depends largely on a variety of factors such as the $\mathrm{pH}$ of the growth environment, the 
(a)

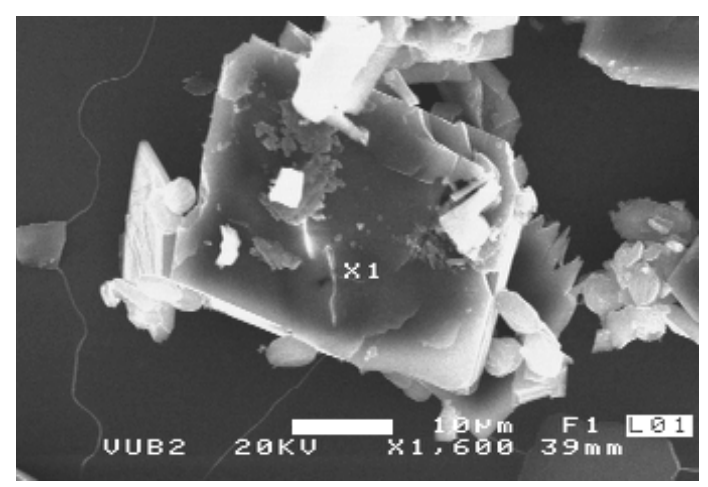

(c)

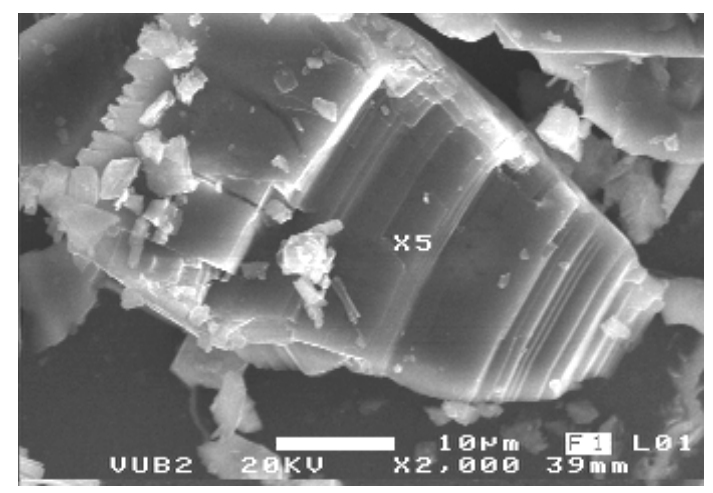

(b)

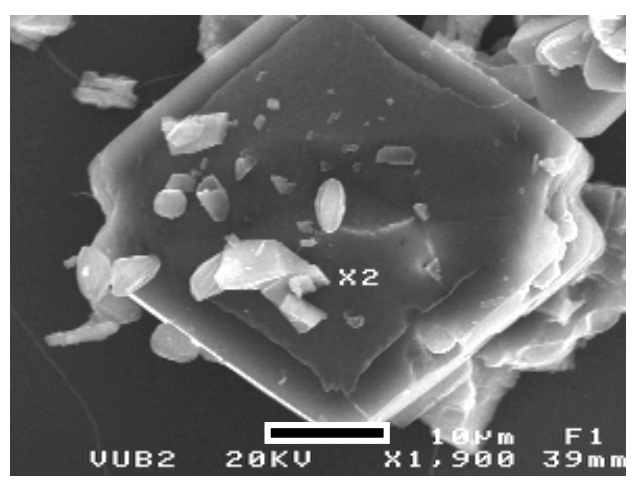

(d)

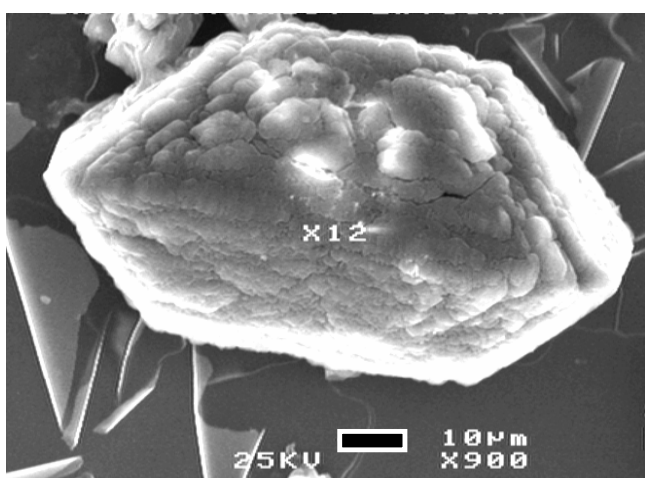

Fig. 11. SEM images of free crystals extracted from the EPS layer showing platy habits (a, b) and coffin shaped habits that are either distorted pyramidal or typical monoclinic $2 / \mathrm{m}$ symmetry forms (c, d). The distorted pyramidal crystals (c) bear transversal lines resembling striations. These lines indicate crystal growth. The platy (pinacoidal) $(a, b)$ and coffin shaped crystals (d) are new crystal habits of glushinskite that formed in fungal culture. Bar scale $=10 \mu \mathrm{m}$.

solubility of oxalates (Gadd, 1999) and diagenetic recrystallization (Verrecchia et al., 1993, 2000), the sequence of formation is driven by the loss of crystallization water: dihydrate oxalates form first, monohydrate second and calcium carbonate $\mathrm{CaCO}_{3}$ third (Verrecchia et al., 1993). Gadd (1999) considered that trihydrate Ca-oxalates are the initial precipitation phase, followed by either the mono- or the dihydrate after losing the water of crystallization. In the present work both types of calcium oxalates (weddellite and whewellite) occur simultaneously in the growth environment. Diagenetic factors cannot play a major role in the transformation of weddellite into whewellite considering the short experimental time. The co-existence of the two mineral species is attributed to fungal metabolic activities (Horner et al, 1995).

In natural growth environment, subaerial fungi can use wind blown particles, rain or the substrate as sources of $\mathrm{Ca}$ for precipitating oxalates (Braissant et al., 2004). In this study, the only source of $\mathrm{Ca}$ and $\mathrm{Mg}$ is the dolomite $(\mathrm{CaMg}$ $\left.\mathrm{CO}_{3}\right)_{2}$ ) substrate and the seawater. Oxalic and carbonic acids cause dissolution of carbonate substrates leading to their sub- sequent weathering and deterioration, which adds an environmental impact to fungal interaction with buildings and works of art made of this material.

Both $\mathrm{Ca}$ and $\mathrm{Mg}$ existed in an unbound form in the seawater growth medium. Thus both metals were available for uptake by fungi. Sayer and Gadd (1997) have demonstrated the fungal ability to form different forms of oxalates, e.g. $\mathrm{Ca}, \mathrm{Cd}, \mathrm{Co}, \mathrm{Cu}, \mathrm{Mn}, \mathrm{Sr}$, and $\mathrm{Zn}$. Howell et al. (2003) have shown that while Ca-oxalates (weddellite and whewellite) were formed by fungal mycobionts of lichens, no magnesium oxalates were detected on the fungal thalli despite the Mg-rich substrates. The fungal culture in the present experiment provided similar results, which could indicate a mechanism of $\mathrm{Mg}$-oxalates formation that differs from that of $\mathrm{Ca}-$ oxalates. 


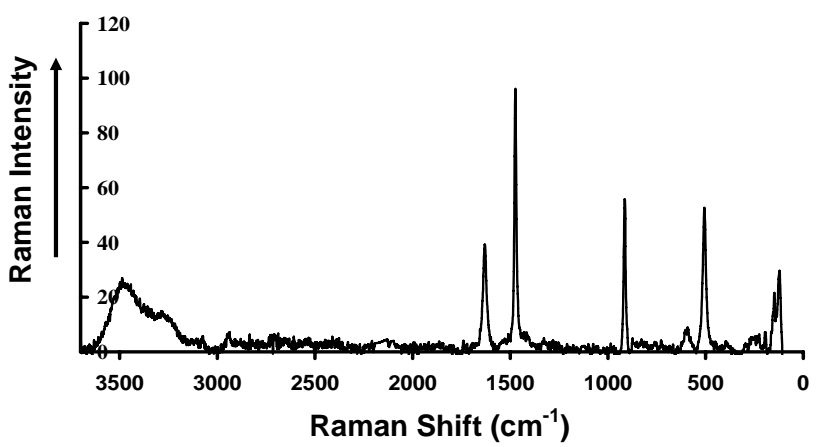

Fig. 12. Raman analysis of single tetragonal prismatic bipyramidal crystals extracted from fungal mass and EPS layer. The spectrum indicates the mineral weddellite. Intense and low bands are observed in the spectrum. The very intense band at $1474 \mathrm{~cm}^{-1}$ is a signature of weddellite.

\subsubsection{Thin section substrates}

\section{A. Ca-oxalates}

The oxalic acid excreted by fungal hyphae reacted with the dolomitic substrate and precipitated $\mathrm{Ca}$ and $\mathrm{Mg}$ oxalates. This process led to dissolution and deterioration of the dolomitic substrate. Carbonic acid $\left(\mathrm{H}_{2} \mathrm{CO}_{3}\right)$ could also form in this environment due to the production of $\mathrm{CO}_{2}$ by fungal bioactivity in the aqueous growth environment (Rosling et al., 2004). In this latter case, high levels of $\mathrm{CO}_{2}$ accumulating in "microenvironments" would produce sufficient concentrations of carbonic acid to induce dissolution of the substrate. This carbonic acid dissolution process also increases the concentration in $\mathrm{Mg}^{2+}$ and $\mathrm{Ca}^{2+}$ cations available to react with oxalic acid and frees the carbonate ions into the growth environment, which contributes to calcium carbonate precipitation. The extensive formation of the biomineralized minerals weddellite and whewellite on the analysed thin sections indicates the high availability of $\mathrm{Ca}^{2+}$ to react with oxalic acid in the fungal growth environment.

Based on SEM observations, the Ca-oxalates within the fungal mass and on the attacked thin sections displayed three precipitation modes:

(i) Direct deposition of tetragonal prismatic dipyramidal crystals $(1-10 \mu \mathrm{m})$ on the attacked substrates of the thin sections (Figs. 2a, b, c and d). Here, the precipitation produced dense new layers of single crystals that either replaced the dissolved original substrate or were deposited directly on it. In the latter case, they filled voids and spaces (created mostly by fungal dissolution of the substrate) between and within the original grains. Fungi also extended the precipitation of biominerals to the rims of the glass slide, outside the primarily attacked area. This suggests fungal capability of mobilising and transporting $\mathrm{Ca}^{2+}$ outside the source area. In

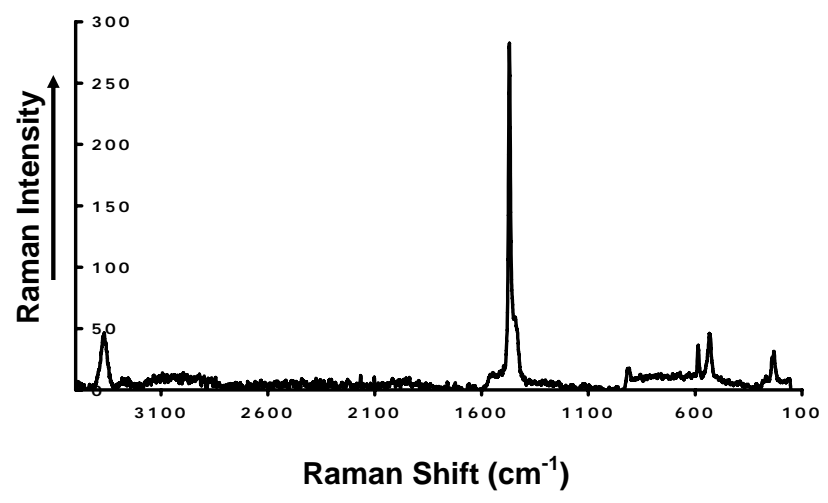

Fig. 13. Raman analysis of single distorted pyramidal crystals (coffin shaped) extracted from fungal mass and EPS layer produced by fungal interaction with SSW substrate. The spectrum indicates the mineral glushinskite with very intense band at $1470 \mathrm{~cm}^{-1}$.

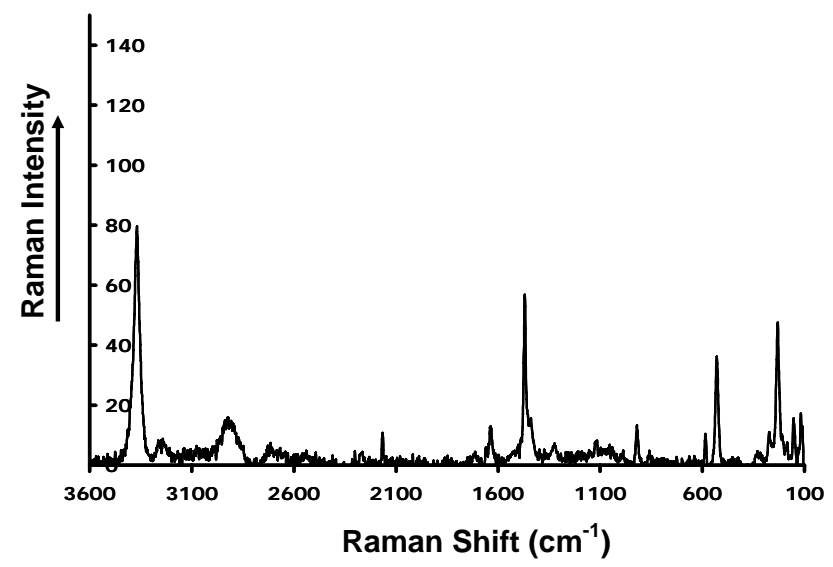

Fig. 14. Raman analysis of single prismatic crystals (coffin shaped) extracted from fungal mass and EPS layer produced by fungal interaction with SSW substrate. The spectrum indicates the mineral glushinskite with very intense band at 3368,1470 and $153 \mathrm{~cm}^{-1}$.

all these cases, the process of forming new substrates or filling the original or created voids can be defined as "biological precipitation" that produces a "micro-biological stratification" similar to the larger scale sedimentary environment.

The abundant fungal spores (size $\approx 2 \mu \mathrm{m}$ ) released into the growth environment come in contact with oxalic acid$\mathrm{Ca}^{2+}$ rich medium where they became nucleation sites for $\mathrm{Ca}$-oxalates. Unlike other free or attached ca-oxalates, these oxalates possess a multi-layer and concentric zonation structures that reflect crystal growth mechanism around a nucleus (Fig. 16). This structure shows a homogenous and equally spaced smooth internal and external growth surfaces. Most of the crystals show a four layer zonation. Unlike the abundant crystals encrusting the fungal hyphae, the $\mathrm{Ca}-$ oxalates deposited around the fungal spores represent prismatic bipyramidal single crystal growth $(4.5 \times 4 \mu \mathrm{m})$. The 


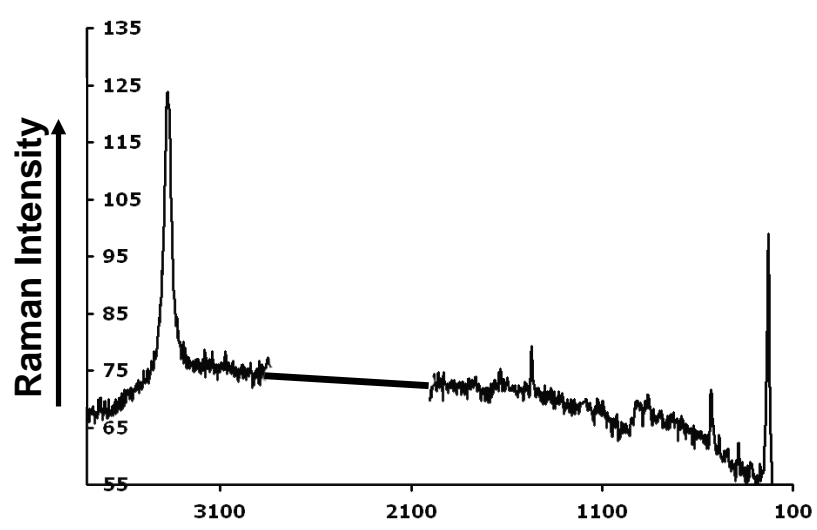

Raman Shift $\left(\mathrm{cm}^{-1}\right)$

Fig. 15. Raman analysis of single platy (pinacoidal) crystals extracted from fungal mass and EPS layer produced by fungal interaction with SSW substrate. The spectrum indicates the mineral glushinskite with very intense bands at 3377 and $229 \mathrm{~cm}^{-1}$. The typical glushinskite band $\left(1470 \mathrm{~cm}^{-1}\right)$ is weak for this crystal habit.

crystals interior and nuclei are square shaped with a depression that represents the spores folding. The nuclei size $(2 \mu \mathrm{m})$ is equal to the size of the spores $(2 \mu \mathrm{m})$. The EDX analysis of such fungal crystals revealed a spectrum similar to normal Ca-oxalates. However, the formation of these zoned crystals reflects chemical changes in growth environment. Despite the fact that these concentric crystals differ in size and shape from sedimentary ooids, their formation in a totally biological environment draws attention to the possibility of formation of similar concentric particles outside sedimentary environments. True fungal ooids have been reported by Krumbein et al. (2003).

(ii) Precipitation on fungal hyphae. Here, a highly ordered envelope of densely packed Ca-oxalate crystals completely engulfs the fungal sheaths at regular spaces (Figs. 2a, b). The highly mineralized fungal hyphae are mostly seen under the microscope as broken fragments even in fresh specimens. The biomineralized fungal hyphae lose their flexibility and become brittle, probably leading to the death of the affected hyphae. Arocena et al. (2001) suggested the deposition of $\mathrm{Ca}$-oxalates on the fungal hyphae surfaces as a protection against dehydration and grazing. The crystals adhere strongly to fungal hyphae, resisting even the mechanical force during extraction. This further indicates that the crystal grows within fungal sheath.

The first and the second modes of precipitation have been described in present day caliches layers, weathering of carbonate buildings or in plants litter (Arnott, 1995; Sterflinger, 2000; Verrecchia, 2000; Garvie, 2003). However, the formation of Ca-oxalates as highly packed and ordered crystal envelopes around the fungal sheaths indicates a direct expulsion of Ca-oxalate through the fungal cellular walls rather

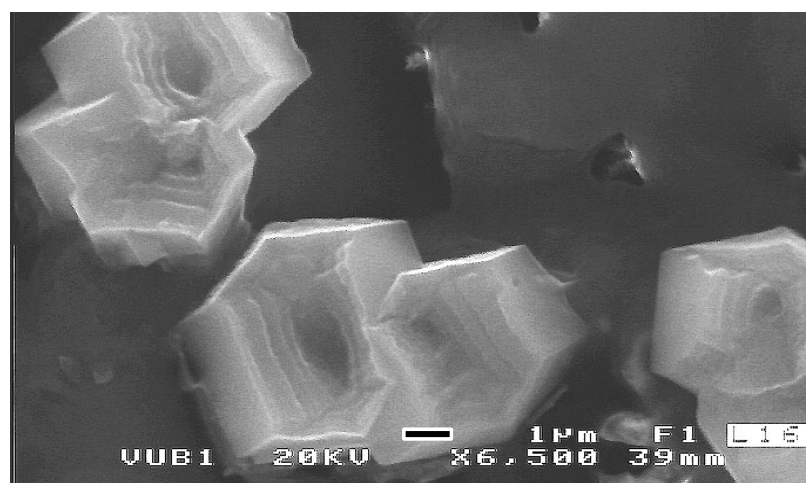

Fig. 16. SEM image of Prismatic bipyramidal Ca-oxalates (weddellite) crystals showing a multi-layer and concentric zonation structures reflecting crystal growth mechanism around a nucleus. Most crystals show a four layer zonation. The crystals nucleated on fungal spores. The size and shape of the nuclei are identical to fungal spores in the growth environment. Black bar scale $=1 \mu \mathrm{m}$.

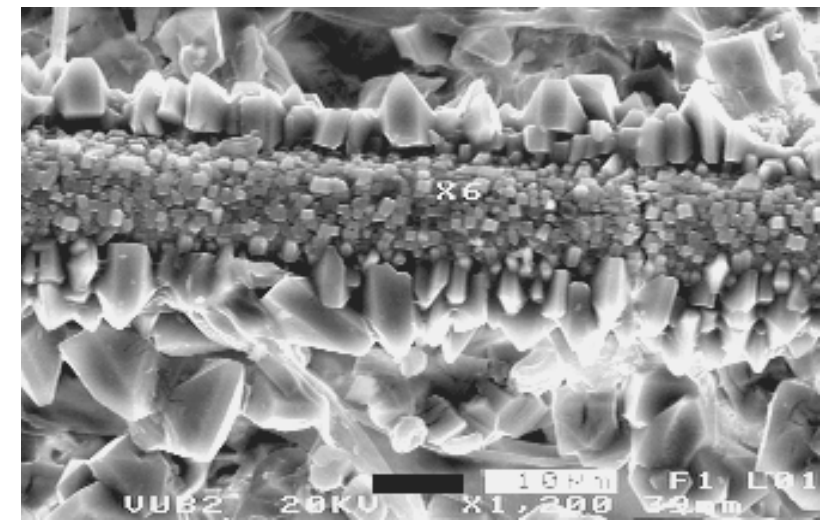

Fig. 17. SEM images showing a double layer of ordered ca-oxalates engulfing fungal sheath reflecting two growth generations. The crystals of the inner and outer layer differ in size, crystal morphology and position. Black bar scale $=10 \mu \mathrm{m}$.

than an exogenous oxalic acid/ $\mathrm{Ca}^{2+}$ reaction and precipitation. The regularity of Ca-oxalates crystals deposition on fungi from plant litter is an indication of the endogenous formation of oxalates followed by expulsion and deposition on the hyphal wall (Arnott, 1995). The occurrence of Caoxalates as ordered and packed deposits on fungal hyphal sheaths together with free Ca-oxalate deposits on attacked substrates indicate that both exogenous and endogenous formation of Ca-oxalates have occurred in the course of this experiment. The intensive biomineralization of fungal hyphae is not a general process. Extensive sampling of the fungal mass demonstrates that biomineralization on fungal hyphae is restricted to the lower parts of fungal hyphae embedded in the EPS layer. Above the EPS layer, hyphae did not show biomineralization. 
SEM images of some fungal hyphae (Fig. 17) show a double layer of ordered ca-oxalates engulfing fungal sheath. The crystals of the inner layer are much smaller $(2-3 \mu \mathrm{m})$ than the second external layer $(5-10 \mu \mathrm{m})$. The growth of two crystal layers suggests two generations separated by a time sequence: a faster inner one and a slower outer one. These two generations are possibly related to the availability of $\mathrm{Ca}$ in the growth environment. With increased fungal attack on the substrate more $\mathrm{Ca}$ is released in the growth environment, which is then immobilized as Ca-oxalates either by direct extracellular expulsion or by reaction of excreted oxalic acid with $\mathrm{Ca}^{+2}$. The crystals of the outer envelope seem to be attached to the fungal hypha by the $\{001\}$ plane. The development of the $\{001\}$ pinacoids seems to be unstable resulting in small $\{001\}$ faces and truncated $\{101\}$ faces. While the crystal morphology of the inner layer type and relation to fungal hyphae have been previously reported (e.g. Arnott, 1995), the double crystal layer and the outer crystal morphology on the hypha are reported here for the first time. The inner crystal layer is densely packed with no apparent orientation to the fungal hypha. The outer layer crystals are orientated perpendicularly to the long hyphal axis resting on the basal pinacoid. Many of these crystals are deeply embedded in the inner layer. The diameter of the inner layer $(\approx 12 \mu \mathrm{m})$ is doubled by the precipitation of the outer crystal layer $(\approx 25 \mu \mathrm{m})$. The EDX analysis shows a $\mathrm{Ca}, \mathrm{O}$ and $\mathrm{C}$ composition. Though not a conclusive analysis, the crystals of the inner envelope seems to show a lower calcium content (26wt \%) than the crystals of the outer envelope (34 wt \%). The mechanism of formation of the double crystal layers on the hypha is not clear. The general homogeneity of the size of outer layer crystals and their embedding in the fungal hyphal wall passing through the inner layer suggest an inner secretion of oxalates.

iii) Precipitation within fungal hyphae. In this case, the Ca-oxalates are lining the inner wall of the fungal sheath (Figs. 2d, e, f), indicating an inner formation of weddellite or whewellite. This third mode of Ca-oxalate formation has been subject of discussion. In higher plants the intracellular formation of Ca-oxalates is well established (Horner and Wagner, 1995). In fungi, the issue of intra-cellular or extra-cellular formation is not fully understood (Vincent et al., 1995). Arnott (1995) demonstrated a sequential expulsion of Ca-oxalates from the hyphal wall. Gadd (1999) reviewed the different arguments pointing towards an intrahyphal formation of oxalates as a cellular detoxification process, where the excess $\mathrm{Ca}$ is neutralized in the form of insoluble oxalates. In the SEM photomicrographs (Figs. 2d, e, f), ordered crystal lining is clearly visible inside the broken fungal hyphae. The crystals form a uniform lining that covers the whole inner curvatures of the broken hollow hyphal sheath. This uniform distribution of the inner lining can occur through endogenous precipitation of the Ca-oxalates.

\section{B. Glushinskite}

Glushinskite as observed under optical microscopy and SEM, showed peculiar crystal morphology. The crystals have a general "spindle" or pear shapes with layered lamellae and locally with transition towards more rhombic or pyramidal morphologies (Figs. 5a, b). The "lamellae", "striations" and "spindle shapes" are common features in the examined glushinskite crystals. Under the optical microscope, the lamellas appear as striations. Wilson (1980) observed at the interface between the lichen Lecanora atra and serpentinite substrates similar striated crystals of naturally formed glushinskite. But the striations on these latter crystals could belong to the other type of glushinskite crystals, namely the distorted pyramidal forms, where they would indicate a growth process involving repetitive twinning. Figures 5a, b also show the genetic relationship between glushinskite and the fungal hyphae. Here glushinskite crystals do not cover or envelope fungal hyphae, but rather appear attached to hyphal tips and sheaths, similar to a fruit-bearing tree, indicating an external reaction of oxalic acid with an $\mathrm{Mg}^{+2}$-rich solution. Glushinskite crystals lie on a layer of finer and more extensively precipitated Ca-oxalates. Garvie (2003) observed the common occurrence of fungal hyphae on the mineral glushinskite and considered that it resulted from the reaction of oxalic acid released by fungi with the $\mathrm{Mg}$-rich solutions supplied by a rotting saguaro cactus.

Glushinskite generally superpose Ca-oxalates in thin sections, indicating a post-Ca-oxalates formation. This sequence of biomineralization could indicate the availability and relative importance of $\mathrm{Ca}$ and $\mathrm{Mg}$ cations in the fungal growth environment. In the case of a dolomitic substrate, it may also illustrate the sequence of possible uptake-expulsion processes for $\mathrm{Ca}^{2+}$ and $\mathrm{Mg}^{2+}$ by fungi. Fungi first neutralize the toxicity of excess $\mathrm{Ca}$ through the Ca up-take and subsequent precipitation of Ca-oxalates (Gadd, 1999; Sterflinger, 2000). This produces solutions rich in $\mathrm{Mg}$ within the fungal growth environment that could precipitate glushinskite. Since the $\mathrm{Mg}$ oxalates have a much higher solubility than $\mathrm{Ca}$ oxalates (Gadd, 1999), the restricted spatial distribution of glushinskite suggests that the high Mg concentrations necessary for its precipitation only prevailed in localized microenvironments.

The peculiar spindle and lamellar crystal morphology of the biomineralized glushinskite could suggest its nucleation on bodies with similar shapes. In Fig. 5c unidentified ornamented round bodies (fungal spores?) with "ribbed" and "ridged" walls, seemingly hollow and with star-shaped ornamentation locally litter some of the spindle shaped glushinskite crystals. Numerous EDX spot analyses of these bodies revealed a high $\mathrm{Mg}$ content. It is possible to speculate that these ribbed and ridged round bodies formed nucleation sites on which the biomineralized glushinskite grew. The formation of zoned structures around spores has been already demonstrated. Lamella growing from the "ribs" formed 
complete spindle shapes in full mineral growth. This offers an additional argument for the exogenous formation of the mineral glushinskite.

\subsubsection{The seawater substrate}

\section{A. Ca-oxalates}

Fungal interaction with the seawater substrate did not produce a substrate of layered Ca-oxalates. Under the optical and SEM microscopy, the Ca-oxalates were either encrusted on the fungal sheaths or embedded in the fungal mass, the former being predominant. The mineral extract produced high abundance of free glushinskite crystals and fewer free Ca-oxalate crystals. Encrustation on fungal hyphae was the main process of Ca-oxalates formation during this interaction. Tetragonal prismatic, bipyramidal and needle prismatic crystals are the observed crystal habits (Figs. 18a, b, c and d). The size and composition are similar to the Ca-oxalates retrieved from the thin section substrates. Here no double encrustations are observed on the fungal sheaths. Small crystals $(1 \mu \mathrm{m})$ protrude perpendicularly from some fungal sheaths (Fig. 18b). These crystals have a wide base on the fungal sheath and a pointed end, making a triangular shape. They appear growing from the hyphal sheath. These growth shapes are interpreted as incipient Ca-oxalates expulsion from fungal sheath. Arnott (1995) observed a similar case of fungi from plant litter. On other hyphae (Figs. 18a, c) rich Ca-oxalates encrustation are observed with tetragonal prismatic and pyramidal crystals with free crystals on the background. The average crystal size is $5 \mu \mathrm{m}$. In Figs. $18 \mathrm{c}$ and d the oxalates encrusting the hyphae are classified as needle prisms. The crystals have high length/width ratio. Some of them show penetration twining. The fungal background is littered with prismatic bipyramidal crystals.

Very interesting is the extent of biomineralization. Figure $18 \mathrm{~d}$ shows total biomineralization of fungal sporangium and hypha with prismatic-needle-type $\mathrm{Ca}$-oxalates. The EDX analysis produced a composition of $\mathrm{Ca}$ only. $\mathrm{Ca}$-oxalates are known to be related to fungal hyphae in various forms, but sporangia are not known to take part in biomineralization as nucleation sites. The crystals' form (needle prisms) and sizes $(1 \times 2 \times 5 \mu \mathrm{m})$ are identical on both fungal hypha and sporangium. The crystals protrude perpendicularly from the hypha or from the sporangium sphere. This suggests a common biomineralization process different from the background, where much larger $(10 \times 10 \times 5 \mu \mathrm{m})$, isolated and tetragonal prismatic and bipyramidal crystals are dominant (Fig. 9a). The formation of similar Ca-crystal forms has been reported as an internal hyphal secretion (Arnott, 1987, 1995; Gadd, 1999). If the hyphal wall is a site for Ca-oxalate formation, then apparently the fungal sporangium plays a critical role. Biomineralization on hyphae and sporangium is induced by indigenous processes through $\mathrm{Ca}$ uptake by fungi from the growth medium and subsequent expulsion of Ca-oxalates, while the background Ca-oxalates, imbedded in fungal mycelium are formed through oxalic acid-Ca reaction in the growth medium.

\section{B. Glushinskite}

Glushinskite, as demonstrated earlier, is represented here by three crystal morphologies, i.e. coffin shaped (distorted-pyramidal and prismatic) and platy (pinacoids). The first two types formed the bulk of the extracted crystals. Similar to the case of the thin section substrate, glushinskite formed within fungal mass embedded in the EPS layer but never encrusted fungal filaments. All of the EDX analyses on crystals enveloping hyphal sheaths produced Ca-bearing mineral only. Glushinskite in its different forms occurred as single, clusters or beads of crystals embedded in the fungal mucilage. The crystals sometimes adhered to fungal hyphae, but never formed ordered encrustations as is the case for Ca-oxalates. This repeated observation confirms the suggestion that during the fungal growth neither $\mathrm{Mg}$ uptake nor $\mathrm{Mg}$ expulsion occurred, contrary to calcium, where both could occur (Jackson and Heath, 1993). The main process of glushinskite formation was exogenous. Oxalic acid secreted by fungi reacted with the free $\mathrm{Mg}$ in the growth medium and precipitated glushinskite in the three different forms. Since the solubility constant of glushinskite is much higher than that of Ca-oxalate monohydrate (Gadd, 1999), fungi respond to $\mathrm{Ca}$ concentration in the growth medium and reaches an equilibrium between $\mathrm{Ca}$ needed for hyphal tip growth process and toxicity of the metal. Excess Ca is excreted outside the cellular walls (Jackson and Heath, 1993) and removed from the growth environment in the form of insoluble $\mathrm{Ca}$-oxalates. This fungal metabolic need for intracellular calcium regulation and the lower solubility constant of Ca-oxalates leads to the formation of a one phase or several phases (e.g. the double encrustations on fungal sheaths) fungal of Ca-oxalates precipitation before $\mathrm{Mg}^{2+}$ attains the concentration necessary to trigger $\mathrm{Mg}$-oxalate precipitation in the growth environment The $\mathrm{Ca}$ was withdrawn from the growth environment before the initiation of glushinskite formation.

\section{Conclusions}

The EDX, Raman and XRD analyses of biomineralized crystals on thin sections and on fungal hyphae (crystal encrustations) have shown that the only Mg-bearing neoformations are those of glushinskite and are crystallized in spindles, foliated, platy and prismatic shapes. The ordered crystals encrustations engulfing fungal hyphae or forming the new substrates are always Ca-oxalates with their specific prismatic, bipyramidal and sometimes rhombic shapes. In this study, glushinskite did not encrust fungal sheaths. This rules out 
(c)
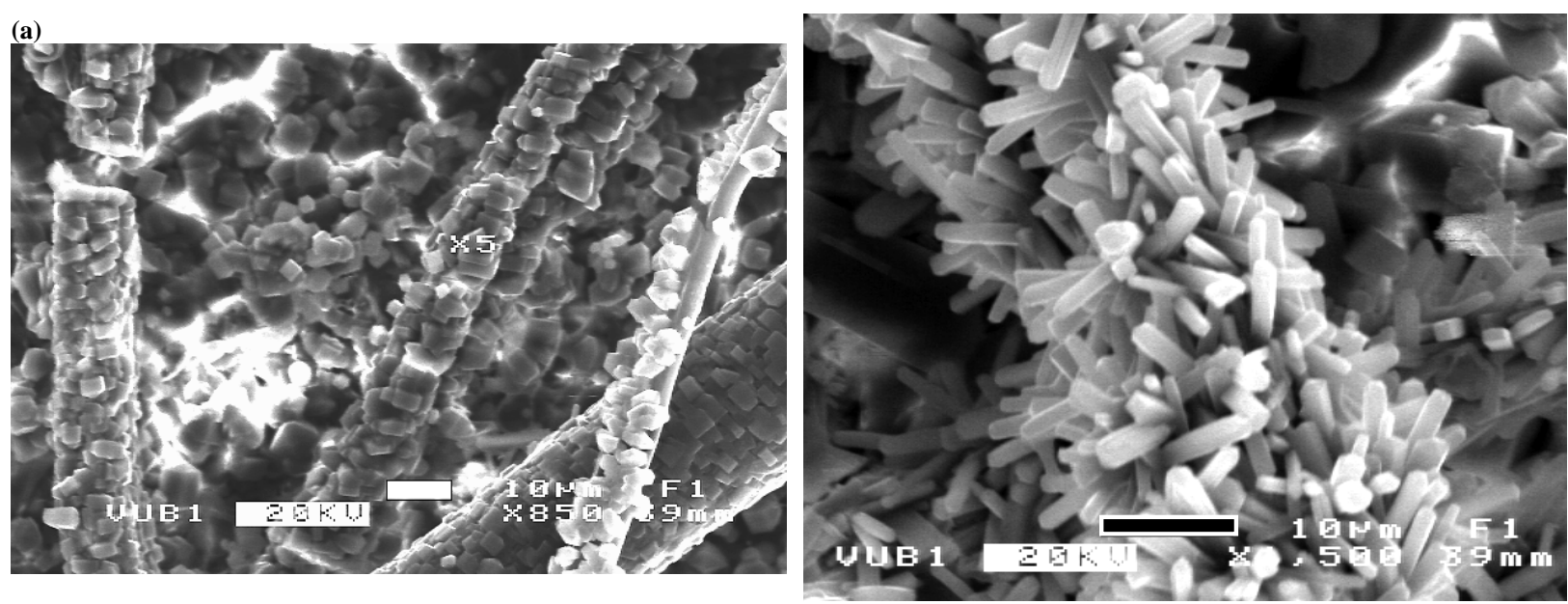

(b)

(d)
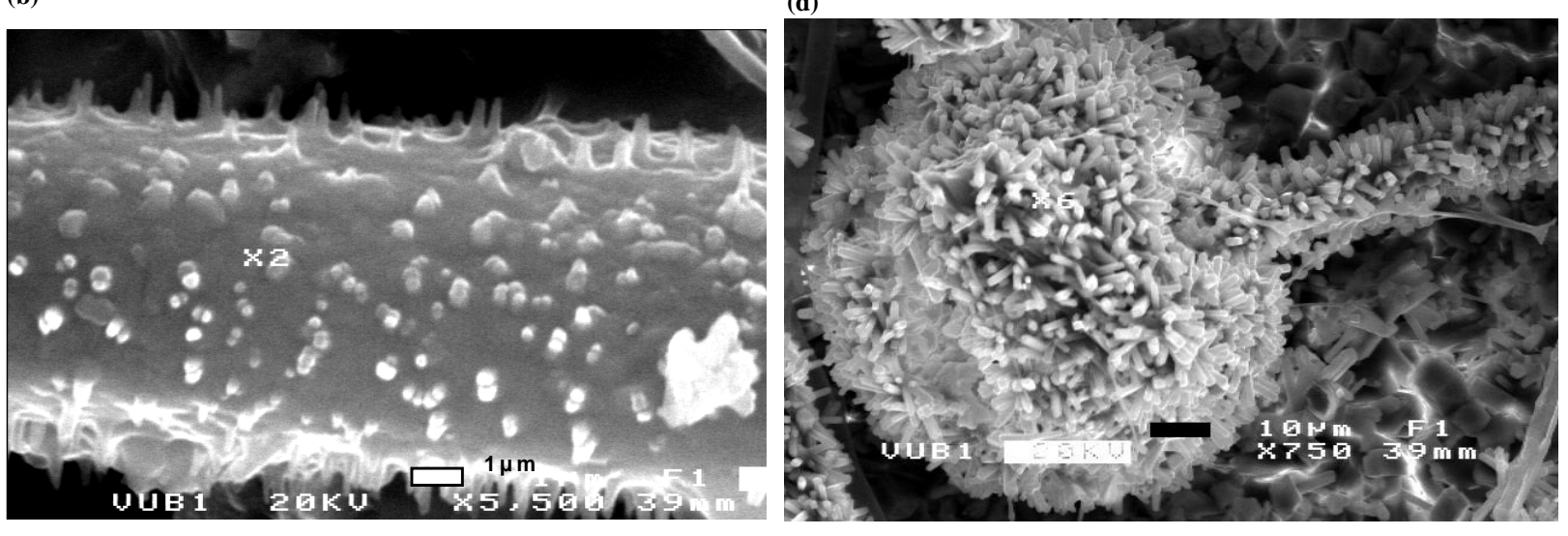

Fig. 18. SEM images of various Ca-oxalates encrustation on fungal hyphae produced by fungal interaction with SSW. Tetragonal prismatic bipyramidal, tetragonal bipyramidal and needle prismatic crystals are the observed crystal habits (a, b, c, d). (a) SEM image of intense biomineralization and encrustation of Ca-oxalates on fungal hyphae produced by fungal interaction with SSW substrate. Free Caoxalate crystals litter the background. The encrustations and free oxalates indicate endogenous and exogenous processes of formation. Bar scale $=10 \mu \mathrm{m}$. (b) SEM image showing incipient biomineralization of Ca-oxalates on fungal sheath produced by fungal interaction with SSW substrate. Small crystals $(1 \mu \mathrm{m})$ are protruding perpendicularly from the fungal sheath. The crystals have wide bases and pointed ends, making a triangular shape. They appear to grow from within the hyphal sheath. Bar scale $=1 \mu \mathrm{m}$. (c) SEM image showing rich Ca-oxalates encrustation of fungal hyphae with needle prism crystals produced by fungal interaction with SSW substrate. The average crystal size is $5 \mu \mathrm{m}$. The crystals have high length/width ratio. Some of them show penetration twining. Bar scale=10 $\mu \mathrm{m}$. (d) SEM image showing total biomineralization of fungal sporangium and hypha with prismatic-needle-type Ca-oxalates produced by fungal interaction with SSW substrate. Sporangia are not known to take part in biomineralization as nucleation sites for Ca-oxalates. The crystal forms (needle prisms) and size $(1 \times 2 \times 5 \mu \mathrm{m})$ are identical on both fungal hypha and sporangium. The crystals protrude vertically from the hypha and from the sporangium sphere. This suggests a common endogenous biomineralization process. bar scale $=10 \mu \mathrm{m}$.

the possibility of $\mathrm{Mg}$-uptake and expulsion as Mg-oxalates. Actually, the much larger glushinskite crystals $(40-100 \mu \mathrm{m})$ compared to Ca-oxalates (usually $<10 \mu \mathrm{m}$ ) suggests slower and longer crystallization processes in localized microenvironments containing high concentrations of $\mathrm{Mg}^{2+}$. The formation of glushinskite is due to a direct reaction between oxalic acid excreted by fungi in the growth environment and the $\mathrm{Mg}^{2+}$ produced by the dissolution of the dolomitic substrate of the thin section. The notions of "biological mineral depo- sition" and the formation of layered stratum (biological stratification) are invoked here again. The Ca-oxalates formed the first deposited "stratum" that was subsequently overlain by a second layer formed of glushinskite. Under natural conditions, where extensive fungal-rock surface interaction is envisaged, this type of microbial deposition could have real geological implications. Lichens cover large areas of exposed rock surfaces almost in any type of environment. Fungi, the mycobiont of lichens interact strongly with rock surfaces 
modifying their chemistry and petrography and causing rock weathering and deposition of biominerals. Fungi growing in vitro from natural airborne spores interact in Petri dishes with dolomitic thin sections and seawater substrates to produce both mineralogical and diagenetic changes on the substrates. Mineralogically, the presence of two cations $\mathrm{Ca}$ and $\mathrm{Mg}$ mobilized by fungi from the substrates and released in the growth environment led to sequential precipitation of $\mathrm{Ca}$ oxalates (weddellite and whewellite) followed by the magnesium dihydrate oxalate: glushinskite. The spatial distribution of this paragenetic sequence produced a "microbiological stratification". The external Ca-oxalates envelope that engulfed whole fungal hyphae indicates an exogenous process of formation. The SEM images of Ca-oxalates lining the inner hyphal walls clearly prove an endogenous formation. Glushinskite compared to Ca-oxalates, only formed exogenously and did not form envelopes on fungal hyphae. Fungal interaction with the dolomitic substrates also produced double-layered encrustations of Ca-oxalates on fungal hyphae. Nucleation on fungal spores produced zoned Caoxalates crystals. Nucleation is also the possible cause of spindle shaped glushinskite. On the seawater substrate, the fungal interaction produced $\mathrm{Ca}$-oxalates and glushinskite by mobilizing $\mathrm{Ca}$ and $\mathrm{Mg}$ from the substrate. Glushinskite could also form in prismatic and platy crystal habits in addition to the known distorted pyramidal habit. Diagenetically, the peculiar forms of substrate dissolution and replacement, biostratification, grain-grain bridging, pore space filling mark the potential imprint left on hard substrates by fungi that together with the fungal organic material within the substrate matrix and the biominerals can form a set of measurable biomarkers for the search of life forms on earth as well as on other planets.

Acknowledgements. We thank J. Vereecken, O. Verstaeten and K. Baerts, Department of Metallurgy, Vrije Universiteit Brussels, for the SEM-EDX and Raman facilities. We also thank A. Bernard, Department of Geology, Université Libre de Bruxelles, for the XRD facility. This work is supported by the Onderzoeksraad van de Vrije Universiteit Brussel.

Edited by: T. W. Lyons

\section{References}

Arnott, H. J.: Calcium oxalates (weddelite) crystals in forest litter, Scan. Electron. Microsc., P3, 1141-114, 1982.

Arnott, H. J.: Calcium oxalates in fungi, in: Calcium Oxalates in Biological Systems, edited by: Khan, S. R., pp. 73-111, CRC press, Boca Raton, 1995.

Arocena, J. M. and Glowa, K. R.: Mineral weathering in ectomycorrhizosphere of subalpine fir (Abies lasiocarpa (Hook.) Nutt.) as revealed by soil solution composition, Forest Ecol. Manag., 133, 61-70, 2000.
Arocena, J. M., Glowa, K. R., and Massicotte, H. B.: Calciumrich hypha encrustations on Piloderma, Mycorrhiza, 10, 209215, 2001.

Arocena, J. M., Zhu, L. P., and Hall, K.: Mineral accumulations induced by biological activity on granitic rocks in Qindhai Plateau, China, Earth Surf. Process. Landf., 28, 1429-1437, 2003.

Ascaso, C., Wierzchos, J., and Castello, R.: Study of the biogenic weathering of calcareous litharenite stones caused by lichens and endolithic microorganisms, Int. Biodeterior. Biodegrad., 42, 2938, 1998.

Bishop, J. L. and Murad, E.: Characterization of minerals and biogeochemical markers on Mars: A Raman and IR spectroscopic study of montmorillonite, J. Raman Spectrosc., 35, 480-486, 2004.

Braissant, O., Cailleau, G., Aragno, M., and Verrecchia, E.: Biologically induced mineralization in the tree Milicia excelsa (Moraceae): its causes and consequences to the environment, Geobiology, 2, 59-66, 2004.

Burford, E. P., Hilier, S., and Gadd, G. M.: Rock and mould: transformation of carbonate minerals by fungi, Abstracts, 7 th Internat. Mycolog. Congr., Oslo, abstract no. 1083, August 2002.

Diaz-Espineira, M., Escolar, E., Bellanato, J., and Medina, J. A.: Crystalline composition of equine urinary sabulous deposits, Scan. Microsc., 9, 1071-1079, 1995.

Edwards, H. G. M., Seaward, M. R. D., Attwood, S. J., Little, S. J., De Oliveira, L. F. C., and Tretiach, M.: FT-Raman spectroscopy of lichens on dolomitic rocks: an assessment of metal oxalate formation, Analyst, 128, 1218-1221, 2003.

Edwards, H. G. M, Villar, J. S. E., Bishop, J. L., and Bloomfield, M.: Raman spectroscopy of sediments from the Antartic Dry Valleys; an analogue study for exploration of potential paleolakes on Mars, J. Raman Spectrosc., 35, 458-462, 2004.

Franceschi, V. R. and Loewus, F. A.: Oxalate biosynthesis and function in plants and fungi, in: Calcium Oxalates in Biological Systems, edited by: Khan, S. R., 113-130, CRC Press, Boca Raton, 1995.

Frost, L. R. and Weier, L. M.: Thermal treatment of weddellite - a Raman and infrared emission spectroscopic study, Thermochm. Acta, 406, 221-232, 2003a.

Frost, L. R. and Weier, L. M.: Raman spectroscopy of natural oxalates at 298 and 77 K, J. Raman Spectrosc., 34, 776-785, 2003b.

Frost, L. R. and Weier, L. M.: Thermal treatment of whewellite a thermal analysis and Raman spectroscopic study, Thermochm. Acta, 409, 79-85, 2004a.

Frost, L. R., Adebajo, M., and Weir, M. L.: A Raman spectroscopic study of thermally treated glushinskite-the natural magnesium oxalate dehydrate, Spectrochimica Acta, part A, 60, 643-651, $2004 b$.

Gadd, G. M.: Fungal production of citric and oxalic acid: importance in metal speciation, physiology and biogeochemical processes, Adv. Microb. Physiol., 41, 47-92, 1999.

Gadd, G. M.: Fungal influence on mineral dissolution and metal mobility: mechanisms and biogeochemical relevance, 12th annual Goldschmidt Conference Abstracts, A257, 2002.

Gadd, G. M., Burford, E. P., Fomina, M., Harper, F. A., and Jacobs, H.: Fungal influence on metal mobility: Mechanisms and relevance to environment and biotechnology, Abstracts, 7th Internat. Mycolog. Cong., Oslo, abstract no. 328, August, 2002. 
Garieb, M. M, Sayer, J. A., and Gadd, G. M.: Solubilization of natural gypsum $\left(\mathrm{CaSO}_{4} \cdot 2 \mathrm{H}_{2} \mathrm{O}\right)$ and the formation of calcium oxalates by Aspergillus niger and Serpula himantiodes, Mycol. Res., 102, 825-830, 1998.

Garvie, L. A. J.: Decay-induced biomineralization of the saguaro cactus (Carnegiea gigantean), Am. Mineral., 88, 1879-1888, 2003.

Garvie, L. A. J., Bungartz, F., Nash, T. H., and Knauth, L. P.: Caliche dissolution and calcite biomineralization by the endolithic lichen Verrucaria rubrocincta Breuss in the Sonoran desert, J. Conf. Absts., 5, 430, 2000.

Hochleitner, R., Tarcea, N., Simon, G., Kiefer, W., and Popp, J.: Micro-Raman spectroscopy: a valuable tool for the investigation of extraterrestrial material, J. Raman Spectro., 35, 515-518, 2004.

Horner, H. T. and Wagner, B. L.: Calcium oxalate formation in higher plants, in: Calcium oxalates in biological systems, edited by: Khan S. R., Boca Raton, FL, USA, CRC Press, 53-75, 1995.

Horner, H. T., Tiffany, L. H., and Knaphus, G.: Oak leaf litter rhizomorphs from Iowa and Texas: calcium oxalate producers, Mycologia, 87, 34-40, 1995.

Jackson, S. L. and Heath, I. B.: Roles of calcium ions in hyphal tip growth, Microbiol. Rev., 57, 367-382, 1993.

Kolo, K., Mamet, B., and Preat, A.: Dichotomous filamentous dolomite crystal growth in the Lower Carboniferous from Northern France: A possible direct production of fungal activity? in: Proc. 1st Geologica Belgica Intern. Meeting, edited by: Degryse, P. and Sintubin, M, 117-120, Leuven, 2002.

Mamet, B. and Préat, A.: Sédimentologie de la Série Viséenne d'Avesnes-Sur-Helpe (Avesnois, Nord de la France), Geologica Belgica, 8, 17-26, 2005.

Preat, A., Kolo, K., Mamet, B., Gorbushina, A., and Gillan, D: Fossil and sub-recent fungal communities in three calcrete series from the Devonian of Canadian Rocky Mountains, Carboniferous of northern France and Cretaceous of central Italy, in: Fossil and Recent Biofilms, edited by: Krumbein, E. W. and Paterson, D. M, Kluwer Academic Publishers, 291-306, 2003.
Rodríguez-Navarro, C., Sebastián, E., and Rodríguez-Gallego, M.: An urban model for dolomite precipitation: Authigenic dolomite on weathered building stones, Sed. Geol., 109, 1-11, 1997.

Rosling, A., Lindhal, B. D., Taylor, A. F. S., and Finlay, R. D.: Mycelial growth and substrate acidification of ectomycorrhizal fungi in response to different minerals, FEMS, Microb. Ecol., 47, 31-37, 2004.

Sayer, J. A. and Gadd, G. M.: Solubilization and transformation of insoluble inorganic metal compounds to insoluble metal oxalates by Aspergillus niger, Mycol. Res., 101, 653-661, 1997.

Silverman, M. P. and Munoz, E. F.: Fungal attack on rock: solubilisation and altered infra red spectra, Science, 169, 985-987, 1970 .

Sterflinger, K.: Fungi as geological agents, Geomicrob. J., 17, 97 124, 2000.

Verrecchia, E. P.: Fungi and Sediments, in: Microbial Sediments, edited by: Riding, R. E. and Awramik, S. M., Springer-Verlag Berlin Heidelberg, 68-75, 2000.

Verrecchia, E. P, Dumont, J. L., and Verrecchia, K. E.: Role of calcium oxalates biomineralization by fungi in the formation of calcretes: A case study from Nazareth, Israel, J. Sed. Geol., 63, 1000-1006, 1993.

Urbanus, J. F. L. M, van den Ende, H., and Koch, B.: Calcium oxalates crystals in the wall of Mucor mucedo, Mycologia, 70, 829-842, 1978.

Wilson, M. J. and Bayliss, P.: Mineral nomenclature: glushinskite, Mineral. Mag., 51, 327, 1987.

Wilson, M. J., Jones, D., and Russel, J. D.: Glushinskite a naturally occurring magnesium oxalate, Mineral. Mag., 43, 837-840, 1980.

Whitney, K. D and Arnott, H. J.: The effect of calcium on mycelial growth and calcium oxalate crystal formation in Gilbertella persicarea (Mucorales), Mycologia, 80, 707-715, 1988. 